\title{
Fixed Point Results for Various $\alpha$-Admissible Contractive Mappings on Metric-Like Spaces
}

\author{
Saleh A. Al-Mezel, ${ }^{1}$ Chi-Ming Chen, ${ }^{2}$ Erdal Karapınar, ${ }^{1,3}$ and Vladimir Rakočevićc ${ }^{4}$ \\ ${ }^{1}$ Nonlinear Analysis and Applied Mathematics Research Group (NAAM), King Abdulaziz University, Jeddah 21491, Saudi Arabia \\ ${ }^{2}$ Department of Applied Mathematics, National Hsinchu University of Education, Taiwan \\ ${ }^{3}$ Department of Mathematics, Atılım University, Incek, 06836 Ankara, Turkey \\ ${ }^{4}$ Faculty of Sciences and Mathematics, University of Niš, Višegradska 33, 18000 Niš, Serbia
}

Correspondence should be addressed to Saleh A. Al-Mezel; salmezel@kau.edu.sa

Received 18 February 2014; Accepted 11 April 2014; Published 11 May 2014

Academic Editor: Ngai-Ching Wong

Copyright (C) 2014 Saleh A. Al-Mezel et al. This is an open access article distributed under the Creative Commons Attribution License, which permits unrestricted use, distribution, and reproduction in any medium, provided the original work is properly cited.

We establish some fixed point theorems for $\alpha$-admissible mappings in the context of metric-like space via various auxiliary functions. In particular, we prove the existence of a fixed point of the generalized Meir-Keeler type $\alpha-\phi$-contractive self-mapping $f$ defined on a metric-like space $X$. The given results generalize, improve, and unify several fixed point theorems for the generalized cyclic contractive mappings that have appeared recently in the literature.

\section{Introduction and Preliminaries}

Nonlinear functional analysis is one of the most dynamic research fields in mathematics. In particular, fixed point theory that has a wide application potential to several quantitative sciences has attracted a number of authors. In the recent decades, several new abstract spaces and new contractive type mappings have been considered to develop the fixed point theory and to increase application potential to existing open problems. Among them, Samet et al. [1] proved very interesting fixed point theorem by introducing the $\alpha$ - $\psi$ contractive self-mapping $f$ in the setting of complete metric space $(X, d)$. In this notion, $\psi$ is a $c$-distance function (see, e.g., [2-5]) and self-mapping is $\alpha$-admissible. The notion of mapping $\alpha$ - $\psi$-contractive mappings has charmed a number of authors (see, e.g., $[1,6-14]$ ).

In this paper, we combine some of the notions to get more general results in the research field of fixed point theory. In particular, we investigate the existence of a fixed point of $\alpha$ admissible mapping in the context of metric-like space via implicit functions.
Throughout this paper, by $\mathbb{R}^{+}$, we denote the set of all nonnegative numbers, while $\mathbb{N}$ is the set of all natural numbers. In 1994, Matthews [15] introduced the following notion of partial metric spaces.

Definition 1 (see [15]). A partial metric on a nonempty set $X$ is a function $p: X \times X \rightarrow[0, \infty)$ such that for all $x, y, z \in X$

$$
\begin{aligned}
& \left(p_{1}\right) x=y \text { if and only if } p(x, x)=p(x, y)=p(y, y) ; \\
& \left(p_{2}\right) p(x, x) \leq p(x, y) ; \\
& \left(p_{3}\right) p(x, y)=p(y, x) ; \\
& \left(p_{4}\right) p(x, y) \leq p(x, z)+p(z, y)-p(z, z) .
\end{aligned}
$$

A partial metric space is a pair $(X, p)$ such that $X$ is a nonempty set and $p$ is a partial metric on $X$.

Remark 2. It is clear that if $p(x, y)=0$, then, from $\left(p_{1}\right)$ and $\left(p_{2}\right), x=y$. But if $x=y, p(x, y)$ may not be 0 . 
Later, fixed point theory has developed rapidly on partial metric spaces; see [16-23]. Further, in 2012, Amini-Harandi [24] introduced the concept of a metric-like space.

Definition 3 (see [24]). A function $\sigma: X \times X \rightarrow[0, \infty)$, where $X$ is a nonempty set, is said to be metric-like on $X$ if the following conditions are satisfied, for all $x, y, z \in X$ :

$$
\begin{aligned}
& \left(\sigma_{1}\right) \text { if } \sigma(x, y)=0 \text {, then } x=y ; \\
& \left(\sigma_{2}\right) \sigma(x, y)=\sigma(y, x) ; \\
& \left(\sigma_{3}\right) \sigma(x, y) \leq \sigma(x, z)+\sigma(z, y) .
\end{aligned}
$$

Then the pair $(X, \sigma)$ is called a metric-like space.

Remark 4 (see [24]). (1) A metric-like on $X$ satisfies all of the conditions of a metric except that $\sigma(x, x)$ may be positive for $x \in X$.

(2) Every partial metric space is a metric-like space. But the converse is not true.

Each metric-like $\sigma$ on $X$ generates a topology $\tau_{\sigma}$ on $X$ whose base is the family of open $\sigma$-balls $\left\{B_{\sigma}(x, \gamma): x \in X, \gamma>\right.$ $0\}$, where $B_{\sigma}(x, \gamma)=\{y \in X:|\sigma(x, y)-\sigma(x, x)|<\gamma\}$ for all $x \in X$ and $\gamma>0$. We recall some definitions on a metric-like space as follows.

Definition 5 (see [24]). Let $(X, \sigma)$ be a metric-like space. Then

(1) a sequence $\left\{x_{n}\right\}$ in a metric-like space $(X, \sigma)$ converges to $x \in X$ if and only if $\sigma(x, x)=$ $\lim _{n \rightarrow \infty} \sigma\left(x_{n}, x\right)$;

(2) a sequence $\left\{x_{n}\right\}$ in a metric-like space $(X, \sigma)$ is called a $\sigma$-Cauchy sequence if and only if $\lim _{m, n \rightarrow \infty} \sigma\left(x_{m}, x_{n}\right)$ exists (and is finite);

(3) a metric-like space $(X, \sigma)$ is said to be complete if every $\sigma$-Cauchy sequence $\left\{x_{n}\right\}$ in $X$ converges, with respect to $\tau_{\sigma}$, to a point $x \in X$ such that

$$
\sigma(x, x)=\lim _{n \rightarrow \infty} \sigma\left(x_{n}, x\right)=\lim _{m, n \rightarrow \infty} \sigma\left(x_{m}, x_{n}\right),
$$

(4) a mapping $T: X \rightarrow X$ is continuous, if the following limits exist (finite) and

$$
\lim _{n \rightarrow \infty} \sigma\left(x_{n}, x\right)=\lim _{m, n \rightarrow \infty} \sigma(T x, x) .
$$

Definition 6 (see [24]). Let $(X, \sigma)$ be a metric-like space and $U$ be a subset of $X$. Then $U$ is a $\sigma$-open subset of $X$ if, for all $x \in X$, there exists $\gamma>0$ such that $B_{\sigma}(x, \gamma) \subset U$. Also, $V \subset X$ is a $\sigma$-closed subset of $X$ if $X \backslash V$ is a $\sigma$-open subset of $X$.

Further, Karapinar and Salimi [25] proved the following crucial properties in the setting of metric-like space $(X, \sigma)$.

Lemma 7 (see [25]). Let $(X, \sigma)$ be a metric-like space. Then

(A) if $\sigma(x, y)=0, \sigma(x, x)=\sigma(y, y)=0$;

(B) if $\left\{x_{n}\right\}$ is a sequence such that $\lim _{n \rightarrow \infty} \sigma\left(x_{n}, x_{n+1}\right)=0$,

$$
\lim _{n \rightarrow \infty} \sigma\left(x_{n}, x_{n}\right)=\lim _{n \rightarrow \infty} \sigma\left(x_{n+1}, x_{n+1}\right)=0 ;
$$

(C) if $x \neq y, \sigma(x, y)>0$;

(D) $\sigma(x, x) \leq(2 / n) \sum_{i=1}^{n} \sigma\left(x, x_{i}\right)$ holds for all $x, x_{i} \in X$, where $1 \leq i \leq n$.

Lemma 8. Let $(X, \sigma)$ be a metric-like space and $\left\{x_{n}\right\}$ be a sequence in $X$ such that $x_{n} \rightarrow x$ as $n \rightarrow \infty$ and $\sigma(x, x)=0$. Then $\lim _{n \rightarrow \infty} \sigma\left(x_{n}, y\right)=\sigma(x, y)$ for all $y \in X$.

We recall the notion of cyclic map which was introduced by Kirk et al. [26]. A mapping $f: A \cup B \rightarrow A \cup B$ is called cyclic if $f(A) \subset B$ and $f(B) \subset A$. Kirk et al. [26] proved the analog of the Banach contraction mapping principle via cyclic mappings.

Theorem 9 (see [26]). Let $A$ and $B$ be two nonempty closed subsets of a complete metric space $(X, d)$, and suppose $f: A \cup$ $B \rightarrow A \cup B$ satisfies the following:

(i) $f$ is a cyclic map,

(ii) $d(f x, f y) \leq k \cdot d(x, y)$ for all $x \in A, y \in B$, and $k \in(0,1)$.

Then $A \cap B$ is nonempty and $f$ has a unique fixed point in $A \cap B$.

Furthermore, Kirk et al. [26] also introduced the following notion of the cyclic representation.

Definition 10 (see [26]). Let $X$ be a nonempty set, $m \in \mathbb{N}$, and $f: X \rightarrow X$ an operator. Then $X=\cup_{i=1}^{m} A_{i}$ is called a cyclic representation of $X$ with respect to $f$ if

(1) $A_{i}, i=1,2, \ldots, m$, are nonempty subsets of $X$;

(2) $f\left(A_{1}\right) \subset A_{2}, f\left(A_{2}\right) \subset A_{3}, \ldots, f\left(A_{m-1}\right) \subset A_{m}$, and $f\left(A_{m}\right) \subset A_{1}$.

By using the notion in the definition above, Kirk et al. [26] proved the following theorem.

Theorem 11 (see [26]). Let $(X, d)$ be a complete metric space, $m \in \mathbb{N}, A_{1}, A_{2}, \ldots, A_{m}$ be closed nonempty subsets of $X$, and $X=\cup_{i=1}^{m} A_{i}$. Suppose that $f$ satisfies the following condition:

$$
\begin{array}{r}
d(f x, f y) \leq \psi(d(x, y)), \quad \forall x \in A_{i}, y \in A_{i+1}, \\
i \in\{1,2, \ldots, m\},
\end{array}
$$

where $\psi: \mathbb{R}^{+} \rightarrow \mathbb{R}^{+}$is upper semicontinuous from the right and $0 \leq \psi(t)<t$ for $t>0$. Then $f$ has a fixed point $z \in \cap_{i=1}^{n} A_{i}$.

In 2012, Karapınar et al. [22] investigated the existence and uniqueness of a fixed point for cyclic generalized $\phi-\psi$ contractive type mappings $f: X \rightarrow X$ in the context of partial metric space. Very recently, Karapınar and Salimi [25] improved the results in [22] by introducing the notion of cyclic generalized $\phi$ - $\psi$-contractive mapping $f: X \rightarrow X$. In this paper [25], the authors proved fixed theorems for such a mapping in the setting of a metric-like space $X$ with a cyclic representation of $X$ with respect to $f$.

Definition 12 (see [25]). Let $(X, \sigma)$ be a metric-like space, $A_{1}, A_{2}, \ldots, A_{m}$ be $\sigma$-closed nonempty subsets of $X$, and 
$Y=\cup_{i=1}^{m} A_{i}$. One says that $T: Y \rightarrow Y$ is called a generalized cyclic $\phi$ - $\psi$-contractive mapping if

(1) $Y=\cup_{i=1}^{m} A_{i}$ is a cyclic representation of $Y$ with respect to $T$;

(2) One considers

$$
\begin{gathered}
\psi(t)-\psi(s)+\phi(t)>0 \quad \forall t>0, s=t, \text { or } s=0, \\
\psi(\sigma(T x, T y)) \leq \psi\left(M_{\sigma}(x, y)\right)-\phi\left(M_{\sigma}(x, y)\right), \\
M_{\sigma}(x, y)=\max \{\sigma(x, y), \sigma(x, T x), \sigma(y, T y), \\
\left.\frac{\sigma(x, T y)+\sigma(y, T x)}{4}\right\},
\end{gathered}
$$

for all $x \in A_{i}$ and $y \in A_{i+1}, i=1,2, \ldots, m$, where $\psi: \mathbb{R}^{+} \rightarrow$ $\mathbb{R}^{+}$is nondecreasing and continuous and $\phi: \mathbb{R}^{+} \rightarrow \mathbb{R}^{+}$is lower semicontinuous.

Theorem 13 (see [25]). Let $(X, \sigma)$ be a metric-like space, $A_{1}, A_{2}, \ldots$, be $\sigma$-closed nonempty subsets of $X$, and $Y=$ $\cup_{i=1}^{m} A_{i}$. If $T: Y \rightarrow Y$ is a generalized cyclic $\phi$ - $\psi$-contractive mapping, then $T$ has a fixed point $\nu \in \cap_{i=1}^{n} A_{i}$.

In this study, we also discuss the notion of $\alpha$-admissible mappings. The following definition was introduced in [1].

Definition 14 (see [1]). For a nonempty set $X$, let $T: X \rightarrow X$ and $\alpha: X \times X \rightarrow[0, \infty)$ be mappings. One says that $f$ is $\alpha$-admissible, if, for all $x, y \in X$, one has

$$
\alpha(x, y) \geq 1 \Longrightarrow \alpha(T x, T y) \geq 1 .
$$

Recall that Samet et al. [1] introduced the following concepts.

Definition 15 (see [1]). Let $(X, d)$ be a metric space and let $T: X \rightarrow X$ be a given mapping. One says that $T$ is an $\alpha-\psi$ contractive mapping if there exist two functions $\alpha: X \times X \rightarrow$ $[0, \infty)$ and a certain $\psi$ such that

$$
\alpha(x, y) d(T x, T y) \leq \psi(d(x, y)), \quad \forall x, y \in X .
$$

It is evident that a mapping satisfying the Banach contraction is a $\alpha-\psi$ contractive mapping equipped with $\alpha(x, y)=1$ for all $x, y \in X$ and $\psi(t)=k t, k \in(0,1)$.

The notion of transitivity of mapping $\alpha: X \times X \rightarrow$ $[0,+\infty)$ was introduced in $[13,14]$ as follows.

Definition 16 (see $[13,14]$ ). Let $N \in \mathbb{N}$. One says that $\alpha$ is $N$ transitive (on $X)$ if

$$
x_{0}, x_{1}, \ldots, x_{N+1} \in X: \alpha\left(x_{i}, x_{i+1}\right) \geq 1,
$$

for all $i \in\{0,1, \ldots, N\} \Rightarrow \alpha\left(x_{0}, x_{N+1}\right) \geq 1$.

In particular, one says that $\alpha$ is transitive if it is 1-transitive; that is,

$$
x, y, z \in X: \alpha(x, y) \geq 1, \quad \alpha(y, z) \geq 1 \Longrightarrow \alpha(x, z) \geq 1 .
$$

As consequences of Definition 16, one obtains the following remarks.

Remark 17 (see $[13,14])$. (1) Any function $\alpha: X \times X \rightarrow$ $[0,+\infty)$ is 0 -transitive.

(2) If $\alpha$ is $N$-transitive, then it is $k N$-transitive for all $k \epsilon$ $\mathbb{N}$.

(3) If $\alpha$ is transitive, then it is $N$-transitive for all $N \in \mathbb{N}$.

(4) If $\alpha$ is $N$-transitive, then it is not necessarily transitive for all $N \in \mathbb{N}$.

In this paper, we investigate the existence and uniqueness of a fixed point of several $\alpha$-admissible mappings in the context of metric-like space. In particular, we establish fixed point theorem for the generalized cyclic Meir-Keeler type $\phi$ - $\alpha$-contractive mappings, the generalized $(\varphi, \phi, \psi, \xi)$ $\alpha$-contractive mappings, and the generalized weaker MeirKeeler type $(\phi, \varphi)$ - $\alpha$-contractive mappings. Our results generalize or improve many recent fixed point theorems for the generalized cyclic contractive mappings in the literature.

\section{Fixed Point Theorem via the $\alpha$-Admissible Meir-Keeler Type Mappings}

In this section, first of all, we will introduce the notion of the generalized Meir-Keeler type $\alpha-\phi$-contractive mappings. Later, we investigate the existence and uniqueness of such mappings in the context of metric-like spaces. We start with recalling the notion of the Meir-Keeler type mappings.

A function $\gamma:[0, \infty) \rightarrow[0, \infty)$ is said to be a MeirKeeler type mapping (see [27]), if, for each $\eta \in[0, \infty)$, there exists $\delta>0$ such that, for $t \in[0, \infty)$ with $\eta \leq t<\eta+\delta$, we have $\gamma(t)<\eta$.

Let $\Phi$ be the class of all function $\phi: \mathbb{R}^{+5} \rightarrow \mathbb{R}^{+}$satisfying the following conditions:

$\left(\phi_{1}\right) \phi$ is an increasing and continuous function in each coordinate;

$\left(\phi_{2}\right)$ for $t>0, \phi(t, t, t, 2 t, 2 t)<t, \phi(t, 0,0, t, t)<t$, and $\phi(0,0, t, t, 0)<t$

$\left(\phi_{3}\right) \phi\left(t_{1}, t_{2}, t_{3}, t_{4}, t_{5}\right)=0$ if and only if $t_{1}=t_{2}=t_{3}=t_{4}=$ $t_{5}=0$.

We will introduce the notion of the generalized MeirKeeler type $\alpha-\phi$-contractive mappings in metric-like spaces as follows.

Definition 18. Let $(X, \sigma)$ be a metric-like space and let $\alpha$ : $X \times X \rightarrow[0, \infty)$. One says that $T: X \rightarrow X$ is called a generalized Meir-Keeler type $\alpha-\phi$-contractive mapping if for each $\eta>0$ there exists $\delta>0$ such that

$$
\begin{aligned}
\eta & \leq \phi(\sigma(x, y), \sigma(x, T x), \sigma(y, T y), \sigma(x, T y), \sigma(y, T x)) \\
& <\eta+\delta \longrightarrow \alpha(x, y) \sigma(T x, T y)<\eta,
\end{aligned}
$$

for all $x, y \in X$ and $\phi \in \Phi$. 
Remark 19. Note that if $T$ is a generalized Meir-Keeler type $\alpha-\phi$-contractive mapping, then we have, for all $x, y \in X$ and $\phi \in \Phi$,

$$
\begin{gathered}
\alpha(x, y) \sigma(T x, T y) \leq \phi(\sigma(x, y), \sigma(x, T x), \sigma(y, T y), \\
\sigma(x, T y), \sigma(y, T x)) .
\end{gathered}
$$

In what follows, we state the main fixed point theorem for a generalized Meir-Keeler type $\alpha-\phi$-contractive mapping in the setting of complete metric-like space.

Theorem 20. Let $(X, \sigma)$ be a complete metric-like space and let $T: X \rightarrow X$ be a generalized Meir-Keeler type $\alpha-\phi$-contractive mapping where $\alpha$ is transitive. Suppose that

(i) $T$ is $\alpha$-admissible;

(ii) there exists $x_{0} \in X$ such that $\alpha\left(x_{0}, T x_{0}\right) \geq 1$;

(iii) $T$ is continuous.

\section{Then there exists $u \in X$ such that $T u=u$.}

Proof. Our proof consists of four steps. In the first step, we prove that $\alpha\left(x_{n}, x_{n+1}\right) \geq 1$, for all $n=0,1, \ldots$. Due to assumption (ii) of the theorem, there exists $x_{0} \in X$ such that $\alpha\left(x_{0}, T x_{0}\right) \geq 1$. We will construct an iterative sequence $\left\{x_{n}\right\}$ in $X$ as follows:

$$
x_{n+1}=T x_{n}=T^{n+1} x_{0} \quad \forall n \geq 0 .
$$

If we have $x_{n_{0}}=x_{n_{0}+1}$, for some $n_{0}$, then the proof is completed. Indeed, $u=x_{n_{0}}$ is a fixed point of $T$. Hence, throughout the proof, we presume that

$$
x_{n} \neq x_{n+1} \quad \forall n .
$$

Since $T$ is $\alpha$-admissible, we have

$$
\begin{aligned}
& \alpha\left(x_{0}, x_{1}\right)=\alpha\left(x_{0}, T x_{0}\right) \geq 1 \\
& \Longrightarrow \alpha\left(T x_{0}, T x_{1}\right)=\alpha\left(x_{1}, x_{2}\right) \geq 1 .
\end{aligned}
$$

By elementary calculations, we derive that

$$
\alpha\left(x_{n}, x_{n+1}\right) \geq 1, \quad \forall n=0,1, \ldots
$$

In the second step, we will prove that $\lim _{n \rightarrow \infty} \sigma\left(x_{n}, x_{n+1}\right)=0$. Notice that we have $\sigma\left(x_{n}, x_{n+1}\right)>0$ for all $n=0,1,2, \ldots$ by (13) and Lemma 7(C). Since $T$ is a generalized Meir-Keeler type $\alpha-\phi$-contractive mapping, by taking $x=x_{n-1}$ and $y=$ $x_{n}$ in (11), we have

$$
\begin{aligned}
& \sigma\left(x_{n}, x_{n+1}\right) \\
& \quad=\sigma\left(T x_{n-1}, T x_{n}\right) \leq \alpha\left(x_{n-1}, x_{n}\right) \sigma\left(T x_{n-1}, T x_{n}\right)
\end{aligned}
$$

$$
\begin{aligned}
& \leq \phi\left(\sigma\left(x_{n-1}, x_{n}\right), \sigma\left(x_{n-1}, T x_{n-1}\right), \sigma\left(x_{n}, T x_{n}\right),\right. \\
& \left.\quad \sigma\left(x_{n-1}, T x_{n}\right), \sigma\left(x_{n}, T x_{n-1}\right)\right) \\
& \leq \phi\left(\sigma\left(x_{n-1}, x_{n}\right), \sigma\left(x_{n-1}, x_{n}\right), \sigma\left(x_{n}, x_{n+1}\right),\right. \\
& \left.\quad \sigma\left(x_{n-1}, x_{n+1}\right), \sigma\left(x_{n}, x_{n}\right)\right) \\
& \leq \phi\left(\sigma\left(x_{n-1}, x_{n}\right), \sigma\left(x_{n-1}, x_{n}\right), \sigma\left(x_{n}, x_{n+1}\right), \sigma\left(x_{n-1}, x_{n}\right)\right. \\
& \left.\quad+\sigma\left(x_{n}, x_{n+1}\right), \sigma\left(x_{n-1}, x_{n}\right)+\sigma\left(x_{n}, x_{n+1}\right)\right) .
\end{aligned}
$$

We assert that $\left\{\sigma\left(x_{n}, x_{n+1}\right)\right\}$ is decreasing; that is, $\sigma\left(x_{n}, x_{n+1}\right)<\sigma\left(x_{n-1}, x_{n}\right)$ for all $n \in \mathbb{N}$. Suppose, on the contrary, that $\sigma\left(x_{n_{0}}, x_{n_{0}+1}\right) \geq \sigma\left(x_{n_{0}-1}, x_{n_{0}}\right)$ for some $n_{0} \in \mathbb{N}$. By taking $x=x_{n_{0}-1}$ and $y=x_{n_{0}}$ in (11) and (16), we have

$$
\begin{aligned}
& \sigma\left(x_{n_{0}}, x_{n_{0}+1}\right) \\
& =\sigma\left(T x_{n_{0}-1}, T x_{n_{0}}\right) \leq \alpha\left(x_{n_{0}-1}, x_{n_{0}}\right) \sigma\left(T x_{n_{0}-1}, T x_{n_{0}}\right) \\
& \leq \phi\left(\sigma\left(x_{n_{0}}, x_{n_{0}+1}\right), \sigma\left(x_{n_{0}}, x_{n_{0}+1}\right), \sigma\left(x_{n_{0}}, x_{n_{0}+1}\right),\right. \\
& \left.\quad 2 \sigma\left(x_{n_{0}}, x_{n_{0}+1}\right), 2 \sigma\left(x_{n_{0}}, x_{n_{0}+1}\right)\right) \\
& <\sigma\left(x_{n_{0}}, x_{n_{0}+1}\right),
\end{aligned}
$$

which is a contradiction. So the $\left\{\sigma\left(x_{n}, x_{n+1}\right)\right\}$ is decreasing, and it must converge to some $\gamma \geq 0$; that is,

$$
\lim _{n \rightarrow \infty} \sigma\left(x_{n}, x_{n+1}\right)=\gamma
$$

By condition $\left(\phi_{1}\right)$, inequality (16) becomes

$$
\begin{aligned}
& \sigma\left(x_{n}, x_{n+1}\right) \\
& =\sigma\left(T x_{n-1}, T x_{n}\right) \\
& \leq \phi\left(\sigma\left(x_{n-1}, x_{n}\right), \sigma\left(x_{n-1}, x_{n}\right), \sigma\left(x_{n-1}, x_{n}\right),\right. \\
& \left.\quad 2 \sigma\left(x_{n-1}, x_{n}\right), 2 \sigma\left(x_{n-1}, x_{n}\right)\right) .
\end{aligned}
$$

We next claim that $\gamma=0$. If not, we assume that $\gamma>0$. By taking limit as $n \rightarrow \infty$ in (19), we have

$$
\begin{aligned}
\gamma & =\lim _{n \rightarrow \infty} \sigma\left(x_{n}, x_{n+1}\right)=\lim _{n \rightarrow \infty} \sigma\left(T x_{n-1}, T x_{n}\right) \\
& \leq \phi(\gamma, \gamma, \gamma, 2 \gamma, 2 \gamma)<\gamma,
\end{aligned}
$$

which is a contradiction. Hence, we have $\gamma=0$.

In the third step, we will prove that $\left\{x_{n}\right\}$ is a $\sigma$-Cauchy sequence. We will use the method of reductio ad absurdum. Suppose, on the contrary, that $\left\{x_{n}\right\}$ is not a $\sigma$-Cauchy sequence. Hence, there exists $\epsilon>0$ and subsequences $\left\{x_{n_{k}}\right\}$ and $\left\{x_{m_{k}}\right\}$ of $\left\{x_{n}\right\}$ with $m_{k}>n_{k} \geq k$ satisfying

$$
\sigma\left(x_{m_{k}}, x_{n_{k}}\right) \geq \epsilon, \quad \sigma\left(x_{m_{k}-1}, x_{n_{k}}\right)<\epsilon .
$$


Since $\alpha$ is transitive, from (15), we have $\alpha\left(x_{n}, x_{n+k}\right) \geq 1$ and hence $\alpha\left(x_{n}, x_{m}\right) \geq 1$. Consider the following:

$$
\begin{aligned}
\epsilon & \leq \sigma\left(x_{m_{k}}, x_{n_{k}}\right) \leq \sigma\left(x_{m_{k}}, x_{m_{k}-1}\right)+\sigma\left(x_{m_{k}-1}, x_{n_{k}}\right) \\
& <\epsilon+\sigma\left(x_{m_{k}}, x_{m_{k}-1}\right) .
\end{aligned}
$$

Letting $k \rightarrow \infty$, we obtain that

$$
\lim _{n \rightarrow \infty} \sigma\left(x_{m_{k}}, x_{n_{k}}\right)=\epsilon .
$$

Also we have

$$
\begin{gathered}
\epsilon \leq \sigma\left(x_{m_{k}}, x_{n_{k}}\right) \leq \sigma\left(x_{m_{k}}, x_{m_{k}+1}\right)+\sigma\left(x_{m_{k}+1}, x_{n_{k}}\right) \\
\sigma\left(x_{m_{k}+1}, x_{n_{k}}\right) \leq \sigma\left(x_{m_{k}+1}, x_{m_{k}}\right)+\sigma\left(x_{m_{k}}, x_{n_{k}}\right) .
\end{gathered}
$$

We get

$$
\begin{aligned}
\epsilon & \leq \sigma\left(x_{m_{k}}, x_{n_{k}}\right) \\
& \leq \sigma\left(x_{m_{k}}, x_{m_{k}+1}\right)+\sigma\left(x_{m_{k}+1}, x_{m_{k}}\right)+\sigma\left(x_{m_{k}}, x_{n_{k}}\right) .
\end{aligned}
$$

Letting $k \rightarrow \infty$ in the inequality above, we find that

$$
\lim _{n \rightarrow \infty} \sigma\left(x_{m_{k}+1}, x_{n_{k}}\right)=\epsilon .
$$

Analogously, we derive that

$$
\lim _{n \rightarrow \infty} \sigma\left(x_{m_{k}}, x_{n_{k}+1}\right)=\epsilon .
$$

Further, we have

$$
\begin{aligned}
\epsilon \leq & \sigma\left(x_{m_{k}}, x_{n_{k}}\right) \leq \sigma\left(x_{m_{k}}, x_{m_{k}+1}\right) \\
& +\sigma\left(x_{m_{k}+1}, x_{n_{k}+1}\right)+\sigma\left(x_{n_{k}+1}, x_{n_{k}}\right) \\
\leq & \sigma\left(x_{m_{k}}, x_{m_{k}+1}\right)+\sigma\left(x_{m_{k}+1}, x_{n_{k}}\right) \\
& +\sigma\left(x_{n_{k}}, x_{n_{k}+1}\right)+\sigma\left(x_{n_{k}+1}, x_{n_{k}}\right) .
\end{aligned}
$$

Letting $k \rightarrow \infty$ in the above inequality, we get that

$$
\lim _{n \rightarrow \infty} \sigma\left(x_{m_{k}+1}, x_{n_{k}+1}\right)=\epsilon
$$

Notice also that

$$
\begin{aligned}
& \sigma\left(x_{m_{k}+1}, x_{n_{k}+1}\right) \\
& =\sigma\left(T x_{m_{k}}, T x_{n_{k}}\right) \leq \alpha\left(x_{m_{k}}, x_{n_{k}}\right) \sigma\left(T x_{m_{k}}, T x_{n_{k}}\right) \\
& \leq \phi\left(\sigma\left(x_{m_{k}}, x_{n_{k}}\right), \sigma\left(x_{m_{k}}, x_{m_{k}+1}\right), \sigma\left(x_{n_{k}}, x_{n_{k}+1}\right),\right. \\
& \left.\sigma\left(x_{m_{k}}, x_{n_{k}+1}\right), \sigma\left(x_{n_{k}}, x_{m_{k}+1}\right)\right) .
\end{aligned}
$$

Letting $k \rightarrow \infty$ in the above inequality and taking the property $\left(\phi_{2}\right)$ into account, we get that

$$
\epsilon=\lim _{n \rightarrow \infty} \sigma\left(x_{q_{n}+1}, x_{p_{n}+1}\right) \leq \phi(\epsilon, 0,0, \epsilon, \epsilon)<\epsilon,
$$

which is a contradiction. Thus, $\left\{x_{n}\right\}$ is a $\sigma$-Cauchy sequence.
In the fourth and last step, we will prove that $T$ has a fixed point $u \in X$. Owing to the fact that $(X, \sigma)$ is complete, there exists $u \in X$ such that $\lim _{n \rightarrow \infty} x_{n}=u$; equivalently,

$$
\sigma(u, u)=\lim _{n \rightarrow \infty} \sigma\left(x_{n}, u\right)=\lim _{m, n \rightarrow \infty} \sigma\left(x_{n}, x_{m}\right)=0 .
$$

Since $T$ is continuous, we obtain from (32) that

$$
\lim _{n \rightarrow \infty} \sigma\left(T x_{n}, T u\right)=\lim _{n \rightarrow \infty} \sigma\left(x_{n}, u\right)=\sigma(u, u)=0 .
$$

Due to Lemma 8, we also have

$$
\lim _{n \rightarrow \infty} \sigma\left(x_{n}, T u\right)=\sigma(u, T u) .
$$

Combining (32)-(34) and Lemma 7(A), we get immediately that $u$ is a fixed point of $T$; that is, $T u=u$.

In the next theorem the continuity of $T$ is not required.

Theorem 21. Let $(X, \sigma)$ be a complete metric-like space and let $T: X \rightarrow X$ be a generalized Meir-Keeler type $\alpha-\phi$-contractive mapping, where $\alpha$ is transitive. Suppose that

(i) $T$ is $\alpha$-admissible;

(ii) there exists $x_{0} \in X$ such that $\alpha\left(x_{0}, T x_{0}\right) \geq 1$;

(iii) if $\left\{x_{n}\right\}$ is a sequence in $X$ such that $\alpha\left(x_{n}, x_{n+1}\right) \geq 1$ for all $n$ and $x_{n} \rightarrow x \in X$ as $n \rightarrow \infty$, then $\alpha\left(x_{n}, x\right) \geq 1$ for all $n$.

Then there exists $u \in X$ such that $T u=u$.

Proof. Following the proof of Theorem 20, we know that the sequence $\left\{x_{n}\right\}$ defined by $x_{n+1}=T x_{n}$, for all $n \geq 0$, converges to $u$ where $u \in X$. It is enough to show that $u \in X$ is the fixed point of $T$. Suppose, on the contrary, that $\sigma(T u, u)=$ $t>0$. From (15) and condition (iii), there exists a subsequence $\left\{x_{n(k)}\right\}$ of $\left\{x_{n}\right\}$ such that $\alpha\left(x_{n(k)}, u\right) \geq 1$ for all $k$. Applying (11), for all $k$, we get that

$$
\begin{gathered}
\sigma\left(x_{n(k)+1}, T u\right) \\
=\sigma\left(T x_{n(k)}, T u\right) \leq \alpha\left(x_{n(k)}, u\right) \sigma\left(T x_{n(k)}, T u\right) \\
\leq \phi\left(\sigma\left(x_{n(k)}, u\right), \sigma\left(x_{n(k)}, T x_{n(k)}\right), \sigma(u, T u),\right. \\
\left.\sigma\left(x_{n(k)}, T u\right), \sigma\left(u, T x_{n(k)}\right)\right) \\
=\phi\left(\sigma\left(x_{n(k)}, u\right), \sigma\left(x_{n(k)}, x_{n(k)+1}\right), \sigma(u, T u),\right. \\
\left.\sigma\left(x_{n(k)}, T u\right), \sigma\left(u, x_{n(k)+1}\right)\right) .
\end{gathered}
$$

Letting $k \rightarrow \infty$ in the above equality and taking (34) into account, we get that

$$
t \leq \phi(0,0, t, t, 0) .
$$

By $\left(\phi_{2}\right)$ we get that

$$
t \leq \phi(0,0, t, t, 0)<t,
$$

which is a contradiction. Thus we get $\sigma(u, T u)=0$, and, by Lemma 7(A), we have $u=T u$. 
For the uniqueness, we need an additional condition.

$(U)$ For all $x, y \in$ Fix $(T)$, we have $\alpha(x, y) \geq 1$, where Fix $(T)$ denotes the set of fixed points of $T$.

In what follows we will show that $u$ is a unique fixed point of $T$.

Theorem 22. Adding condition $(U)$ to the hypotheses of Theorem 20 (resp., Theorem 21), one obtains that $u$ is the unique fixed point of $T$.

Proof. We will use the reductio ad absurdum. Let $v$ be another fixed point of $T$ with $v \neq u$ and hence $\sigma(u, v)=t>0$. By hypothesis $(U)$,

$$
1 \leq \alpha(u, v)=\alpha(T u, T v)
$$

Due to inequality (11) we have

$$
\begin{gathered}
\alpha(u, v) \sigma(T u, T y) \leq \phi(\sigma(u, v), \sigma(u, T u), \sigma(v, T v), \\
\sigma(u, T v), \sigma(v, T u)) .
\end{gathered}
$$

Taking property $\left(\phi_{2}\right)$ into account, we get that

$$
t \leq(t, 0,0, t, t)<t
$$

which is a contradiction. Hence, $\sigma(u, v)=0$. It follows from Lemma $7(\mathrm{~A})$ that $u=v$. Thus we proved that $u$ is the unique fixed point of $T$.

\section{Fixed Point Theorem via Auxiliary Functions}

In the section, we will discuss the notion of generalized $(\varphi, \phi, \psi, \xi)-\alpha$-contractive mappings and prove fixed point theorems for these mappings in complete metric-like spaces. We denote by $\Psi$ the class of functions $\psi: \mathbb{R}^{+} \rightarrow \mathbb{R}^{+}$ satisfying the following conditions:

$\left(\psi_{1}\right) \psi$ is continuous and nondecreasing;

$\left(\psi_{2}\right) \psi(t)>0$ for all $t>0$ and $\psi(0)=0$.

Let $\Phi_{\psi}$ be the class of all function $\phi: \mathbb{R}^{+5} \rightarrow \mathbb{R}^{+}$ satisfying the following conditions:

$\left(\phi_{1}\right) \phi$ is an increasing and continuous function in each coordinate;

$\left(\phi_{2}\right)$ for $t>0, \phi(\psi(t), \psi(t), \psi(t), \psi(2 t), \psi(2 t)) \leq \psi(t)$, $\phi(t, 0,0, t, t) \leq t$, and $\phi(0,0, t, t, 0) \leq t$, where $\psi \in \Psi$;

$\left(\phi_{3}\right) \phi\left(t_{1}, t_{2}, t_{3}, t_{4}, t_{5}\right)=0$ if and only if $t_{1}=t_{2}=t_{3}=t_{4}=$ $t_{5}=0$.

We use the following notations to specify the collection of the given functions:

$$
\begin{gathered}
\Xi=\left\{\xi: \mathbb{R}^{+} \longrightarrow \mathbb{R}^{+}: \xi \text { is lower continuous }\right\}, \\
\Theta=\left\{\varphi: \mathbb{R}^{+} \longrightarrow \mathbb{R}^{+}: \varphi \text { is continuous }\right\} .
\end{gathered}
$$

We now state the new notion of generalized $(\varphi, \phi, \psi, \xi)$ $\alpha$-contractive mappings in metric-like spaces is as follows.
Definition 23. Let $(X, \sigma)$ be a metric-like space and let $\alpha: X \times$ $X \rightarrow \mathbb{R}^{+}$. One says that $T$ is called a generalized $(\varphi, \phi, \psi, \xi)$ $\alpha$-contractive mapping if $T$ is $\alpha$-admissible and satisfies the following inequality:

$$
\begin{aligned}
& \alpha(x, y) \varphi(\sigma(T x, T y)) \\
& \leq \phi(\psi(\sigma(x, y)), \psi(\sigma(x, T x)), \psi(\sigma(y, T y)), \\
&\psi(\sigma(x, T y)), \psi(\sigma(y, T x))) \\
&-\xi(\max \{\sigma(x, y), \sigma(x, T x), \sigma(y, T y), \\
&\left.\left.\frac{\sigma(x, T y)+\sigma(y, T x)}{4}\right\}\right),
\end{aligned}
$$

for all $x, y \in X$, where $\psi \in \Psi, \phi \in \Phi_{\psi}, \varphi \in \Theta$, and $\xi \in \Xi$.

One now states the main fixed point of this section as follows.

Theorem 24. Let $(X, \sigma)$ be a complete metric-like space and let $T: X \rightarrow X$ be a $(\varphi, \phi, \psi, \xi)$ - $\alpha$-contractive mapping where $\alpha$ is transitive. Suppose that

(i) $T$ is $\alpha$-admissible;

(ii) there exists $x_{0} \in X$ such that $\alpha\left(x_{0}, T x_{0}\right) \geq 1$;

(iii) $T$ is continuous.

Then there exists $u \in X$ such that $T u=u$.

Proof. As in the proof of Theorem 20, we construct an iterative sequence $\left\{x_{n}\right\}$ in $X$ as follows:

$$
x_{n+1}=T x_{n}=T^{n+1} x_{0} \quad \forall n \geq 0 .
$$

If we have $x_{n_{0}}=x_{n_{0}+1}$, for some $n_{0}$, then the proof is completed. Indeed, $u=x_{n_{0}}$ is a fixed point of $T$. Hence, from now on, we assume that

$$
x_{n} \neq x_{n+1} \quad \forall n \text {. }
$$

Moreover, due to Lemmas 7(C) and (D), we have

$$
\sigma\left(x_{n}, x_{n+1}\right)>0
$$

Again, as in the proof of Theorem 20, since $T$ is $\alpha$-admissible, we deduce that

$$
\alpha\left(x_{n}, x_{n+1}\right) \geq 1, \quad \forall n=0,1, \ldots
$$


Owing to the fact that $T$ is a generalized $(\varphi, \phi, \psi, \xi)-\alpha-$ contraction, by taking $x=x_{n-1}$ and $y=x_{n}$ in (42), we have

$$
\begin{aligned}
& \varphi\left(\sigma\left(x_{n}, x_{n+1}\right)\right) \\
& =\varphi\left(\sigma\left(T x_{n-1}, T x_{n}\right)\right) \leq \alpha\left(x_{n-1}, x_{n}\right) \varphi\left(\sigma\left(T x_{n-1}, T x_{n}\right)\right) \\
& \leq \phi\left(\psi\left(\sigma\left(x_{n-1}, x_{n}\right)\right), \psi\left(\sigma\left(x_{n-1}, T x_{n-1}\right)\right),\right. \\
& \psi\left(\sigma\left(x_{n}, T x_{n}\right)\right) \\
& \left.\psi\left(\sigma\left(x_{n-1}, T x_{n}\right)\right), \psi\left(\sigma\left(x_{n}, T x_{n-1}\right)\right)\right) \\
& -\xi\left(\operatorname { m a x } \left\{\sigma\left(x_{n-1}, x_{n}\right), \sigma\left(x_{n-1}, T x_{n-1}\right), \sigma\left(x_{n}, T x_{n}\right)\right.\right. \text {, } \\
& \left.\left.\frac{\sigma\left(x_{n-1}, T x_{n}\right)+\sigma\left(x_{n}, T x_{n-1}\right)}{4}\right\}\right) \\
& \leq \phi\left(\psi\left(\sigma\left(x_{n-1}, x_{n}\right)\right), \psi\left(\sigma\left(x_{n-1}, x_{n}\right)\right), \psi\left(\sigma\left(x_{n}, x_{n+1}\right)\right),\right. \\
& \left.\psi\left(\sigma\left(x_{n-1}, x_{n+1}\right)\right), \psi\left(\sigma\left(x_{n}, x_{n}\right)\right)\right) \\
& -\xi\left(\operatorname { m a x } \left\{\sigma\left(x_{n-1}, x_{n}\right), \sigma\left(x_{n-1}, x_{n}\right), \sigma\left(x_{n}, x_{n+1}\right),\right.\right. \\
& \left.\left.\frac{\sigma\left(x_{n-1}, x_{n+1}\right)+\sigma\left(x_{n}, x_{n}\right)}{4}\right\}\right) \\
& \leq \phi\left(\psi\left(\sigma\left(x_{n-1}, x_{n}\right)\right), \psi\left(\sigma\left(x_{n}, x_{n+1}\right)\right),\right. \\
& \psi\left(\sigma\left(x_{n-1}, x_{n}\right)+\sigma\left(x_{n}, x_{n+1}\right)\right), \\
& \left.\psi\left(\sigma\left(x_{n-1}, x_{n}\right)+\sigma\left(x_{n}, x_{n+1}\right)\right)\right) \\
& -\xi\left(\operatorname { m a x } \left\{\sigma\left(x_{n-1}, x_{n}\right), \sigma\left(x_{n-1}, x_{n}\right), \sigma\left(x_{n}, x_{n+1}\right)\right.\right. \text {, } \\
& \left.\left.\frac{\sigma\left(x_{n-1}, x_{n}\right)+\sigma\left(x_{n}, x_{n+1}\right)}{2}\right\}\right) \text {. }
\end{aligned}
$$

As a first step, we prove that

$$
\lim _{n \rightarrow \infty} \sigma\left(x_{n}, x_{n+1}\right)=0
$$

For this goal, we show that $\left\{\sigma\left(x_{n}, x_{n+1}\right)\right\}$ is decreasing; that is, $\sigma\left(x_{n}, x_{n+1}\right)<\sigma\left(x_{n-1}, x_{n}\right)$ for all $n \in \mathbb{N}$. Suppose, on the contrary, that $\sigma\left(x_{n_{0}}, x_{n_{0}+1}\right) \geq \sigma\left(x_{n_{0}-1}, x_{n_{0}}\right)$ for some $n_{0} \in \mathbb{N}$. By substituting $x=x_{n_{0}-1}$ and $y=x_{n_{0}}$ in (42) and (47), we have

$$
\begin{aligned}
& \varphi\left(\sigma\left(x_{n_{0}}, x_{n_{0}+1}\right)\right) \\
& \quad=\varphi\left(\sigma\left(T x_{n_{0}-1}, T x_{n_{0}}\right)\right) \\
& \quad \leq \alpha\left(x_{n_{0}-1}, x_{n_{0}}\right) \varphi\left(\sigma\left(T x_{n_{0}-1}, T x_{n_{0}}\right)\right)
\end{aligned}
$$

$$
\begin{aligned}
\leq \phi & \psi\left(\sigma\left(x_{n_{0}}, x_{n_{0}+1}\right)\right), \psi\left(\sigma\left(x_{n_{0}}, x_{n_{0}+1}\right)\right), \\
& \psi\left(\sigma\left(x_{n_{0}}, x_{n_{0}+1}\right)\right), \\
& \left.\psi\left(2 \sigma\left(x_{n_{0}}, x_{n_{0}+1}\right)\right), \psi\left(2 \sigma\left(x_{n_{0}}, x_{n_{0}+1}\right)\right)\right) \\
- & \xi\left(\sigma\left(x_{n_{0}}, x_{n_{0}+1}\right)\right) \\
\leq & \psi
\end{aligned}
$$

Regarding the condition $\varphi(t)-\psi(t)+\xi(t)>0$ for all $t>0$ and by using inequality (49), we derive that $\sigma\left(x_{n_{0}}, x_{n_{0}+1}\right)=0$, which contradicts to (45). Hence, we deduce that

$$
\sigma\left(x_{n}, x_{n+1}\right)<\sigma\left(x_{n-1}, x_{n}\right) \quad \forall n \in \mathbb{N} \text {. }
$$

From the arguments above, we also have, for each $n \in \mathbb{N}$,

$$
\begin{aligned}
\varphi\left(\sigma\left(x_{n}, x_{n+1}\right)\right) & =\varphi\left(\sigma\left(T x_{n-1}, T x_{n}\right)\right) \\
& \leq \psi\left(\sigma\left(x_{n-1}, x_{n}\right)\right)-\xi\left(\sigma\left(x_{n-1}, x_{n}\right)\right)
\end{aligned}
$$

It follows from (50) that the sequence $\left\{\sigma\left(x_{n}, x_{n+1}\right)\right\}$ is monotone decreasing. Hence, it should be convergent to some $\eta \geq$ 0 ; that is,

$$
\lim _{n \rightarrow \infty} \sigma\left(x_{n}, x_{n+1}\right)=\eta
$$

Letting $n \rightarrow \infty$ in (51) and by using the continuities of $\psi$ and $\varphi$ and the lower semicontinuity of $\xi$, we have

$$
\varphi(\eta) \leq \psi(\eta)-\xi(\eta)
$$

which implies that $\eta=0$.

As in the proof of Theorem 20, we will use the same techniques, method of reductio ad absurdum, to prove that $\left\{x_{n}\right\}$ is a $\sigma$-Cauchy sequence. Suppose, on the contrary, that $\left\{x_{n}\right\}$ is not a $\sigma$-Cauchy sequence. Hence, there exists $\epsilon>0$ and subsequences $\left\{x_{n_{k}}\right\}$ and $\left\{x_{m_{k}}\right\}$ of $\left\{x_{n}\right\}$ with $m_{k}>n_{k} \geq k$ satisfying

$$
\sigma\left(x_{m_{k}}, x_{n_{k}}\right) \geq \epsilon, \quad \sigma\left(x_{m_{k}-1}, x_{n_{k}}\right)<\epsilon
$$

By repeating the related lines in the proof of Theorem 20, we find the following limits:

$$
\begin{aligned}
\lim _{n \rightarrow \infty} \sigma\left(x_{m_{k}}, x_{n_{k}}\right) & =\lim _{n \rightarrow \infty} \sigma\left(x_{m_{k}+1}, x_{n_{k}}\right) \\
& =\lim _{n \rightarrow \infty} \sigma\left(x_{m_{k}}, x_{n_{k}+1}\right) \\
& =\lim _{n \rightarrow \infty} \sigma\left(x_{m_{k}+1}, x_{n_{k}+1}\right)=\epsilon .
\end{aligned}
$$


By assumption of the theorem, we have

$$
\begin{aligned}
& \sigma\left(x_{m_{k}+1}, x_{n_{k}+1}\right) \\
& =\sigma\left(T x_{m_{k}}, T x_{n_{k}}\right) \leq \alpha\left(x_{m_{k}}, x_{n_{k}}\right) \sigma\left(T x_{m_{k}}, T x_{n_{k}}\right) \\
& \leq \phi\left(\psi\left(\sigma\left(x_{n_{k}}, x_{m_{k}}\right)\right), \psi\left(\sigma\left(x_{n_{k}}, T x_{n_{k}}\right)\right),\right. \\
& \psi\left(\sigma\left(x_{m_{k}}, T x_{m_{k}}\right)\right) \\
& \left.\psi\left(\sigma\left(x_{n_{k}}, T x_{m_{k}}\right)\right), \psi\left(\sigma\left(x_{m_{k}}, T x_{n_{k}}\right)\right)\right) \\
& -\xi\left(\operatorname { m a x } \left\{\sigma\left(x_{n_{k}}, x_{m_{k}}\right), \sigma\left(x_{n_{k}}, T x_{n_{k}}\right),\right.\right. \\
& \sigma\left(x_{m_{k}}, T x_{m_{k}}\right), \\
& \left.\left.\frac{\sigma\left(x_{n_{k}}, x_{m_{k}+1}\right)+\sigma\left(x_{m_{k}}, T x_{n_{k}}\right)}{4}\right\}\right) \\
& \leq \phi\left(\psi\left(\sigma\left(x_{n_{k}}, x_{m_{k}}\right)\right), \psi\left(\sigma\left(x_{n_{k}}, x_{n_{k}+1}\right)\right),\right. \\
& \psi\left(\sigma\left(x_{m_{k}}, T x_{m_{k}}\right)\right), \\
& \left.\psi\left(\sigma\left(x_{n_{k}}, x_{m_{k}+1}\right)\right), \psi\left(\sigma\left(x_{m_{k}}, x_{n_{k}+1}\right)\right)\right) \\
& -\xi\left(\operatorname { m a x } \left\{\sigma\left(x_{n_{k}}, x_{m_{k}}\right), \sigma\left(x_{n_{k}}, x_{n_{k}+1}\right)\right.\right. \text {, } \\
& \sigma\left(x_{m_{k}}, x_{m_{k}+1}\right), \\
& \left.\left.\frac{\sigma\left(x_{n_{k}}, x_{m_{k}+1}\right)+\sigma\left(x_{m_{k}}, x_{n_{k}+1}\right)}{4}\right\}\right) \text {. }
\end{aligned}
$$

Letting $n \rightarrow \infty$ in (56), we find that

$$
\varphi(\epsilon) \leq \phi(\psi(\epsilon), 0,0, \psi(\epsilon), \psi(\epsilon))-\xi(\epsilon) \leq \psi(\epsilon)-\xi(\epsilon),
$$

which implies that $\epsilon=0$. This is a contradiction. Therefore, the sequence $\left\{x_{n}\right\}$ is a $\sigma$-Cauchy sequence.

As a last step, we will prove that $T$ has a fixed point $u \in X$. Owing to the fact that $(X, \sigma)$ is complete, there exists $u \in X$ such that $\lim _{n \rightarrow \infty} x_{n}=u$, equivalently,

$$
\sigma(u, u)=\lim _{n \rightarrow \infty} \sigma\left(x_{n}, u\right)=\lim _{m, n \rightarrow \infty} \sigma\left(x_{n}, x_{m}\right)=0 .
$$

Since $T$ is continuous, we obtain from (58) that

$$
\lim _{n \rightarrow \infty} \sigma\left(T x_{n}, T u\right)=\lim _{n \rightarrow \infty}=\sigma\left(x_{n}, u\right)=\sigma(u, u)=0 .
$$

Due to Lemma 8, we also have

$$
\lim _{n \rightarrow \infty} \sigma\left(x_{n}, T u\right)=\sigma(u, T u) .
$$

On account of (58)-(60) and Lemma 7(A), we derive that $u$ is a fixed point of $T$; that is, $T u=u$.
Theorem 25. Let $(X, \sigma)$ be a complete metric-like space and let $T: X \rightarrow X$ be $a(\varphi, \phi, \psi, \xi)$ - $\alpha$-contractive mapping where $\alpha$ is transitive. Suppose that

(i) $T$ is $\alpha$-admissible;

(ii) there exists $x_{0} \in X$ such that $\alpha\left(x_{0}, T x_{0}\right) \geq 1$;

(iii) if $\left\{x_{n}\right\}$ is a sequence in $X$ such that $\alpha\left(x_{n}, x_{n+1}\right) \geq 1$ for all $n$ and $x_{n} \rightarrow x \in X$ as $n \rightarrow \infty$, then $\alpha\left(x_{n}, x\right) \geq 1$ for all $n$.

Then there exists $u \in X$ such that $T u=u$.

Proof. Following the proof of Theorem 24, we know that the sequence $\left\{x_{n}\right\}$ defined by $x_{n+1}=T x_{n}$, for all $n \geq 0$, converges to $u$ where $u \in X$. It is enough to show that $u \in X$ is the fixed point of $T$. Suppose, on the contrary, that $\sigma(T u, u)=t>$ 0 . From (46) and condition (iii), there exists a subsequence $\left\{x_{n(k)}\right\}$ of $\left\{x_{n}\right\}$ such that $\alpha\left(x_{n(k)}, u\right) \geq 1$ for all $k$. Applying (42), for all $k$, we get that

$$
\begin{gathered}
\sigma\left(x_{n(k)+1}, T u\right) \\
=\sigma\left(T x_{n(k)}, T u\right) \leq \alpha\left(x_{n(k)}, u\right) \sigma\left(T x_{n(k)}, T u\right) \\
\leq \phi\left(\psi\left(\sigma\left(x_{n(k)}, u\right)\right), \psi\left(\sigma\left(x_{n(k)}, T x_{n(k)}\right)\right), \psi(\sigma(u, T u)),\right. \\
\left.\psi\left(\sigma\left(x_{n(k)}, T u\right)\right), \psi\left(\sigma\left(u, T x_{n(k)}\right)\right)\right) \\
-\xi\left(\operatorname { m a x } \left\{\sigma\left(x_{n(k)}, u\right), \sigma\left(x_{n(k)}, T x_{n(k)}\right), \sigma(u, T u),\right.\right. \\
=\phi\left(\psi\left(\sigma\left(x_{n(k)}, u\right)\right), \psi\left(\sigma\left(x_{n(k)}, x_{n(k)+1}\right)\right), \psi(\sigma(u, T u)),\right. \\
\left.\psi\left(\sigma\left(x_{n(k)}, T u\right)\right), \psi\left(\sigma\left(u, x_{n(k)+1}\right)\right)\right) \\
-\xi\left(\operatorname { m a x } \left\{\sigma\left(x_{n(k)}, u\right), \sigma\left(x_{n(k)}, x_{n(k)+1}\right), \sigma(u, T u),\right.\right. \\
\left.\left.\frac{\sigma\left(x_{n(k)}, T u\right)+\sigma\left(u, x_{n(k)+1}\right)}{4}\right\}\right) .
\end{gathered}
$$

Letting $k \rightarrow \infty$ in the above equality and taking (60) into account, we get that

$$
t \leq \phi(0,0, t, t, 0)-\xi(t) \leq \phi(0,0, t, t, 0) .
$$

By $\left(\psi_{2}\right)$ we get that

$$
t \leq \phi(0,0, t, t, 0)<t,
$$

which is a contradiction. Thus we get $\sigma(u, T u)=0$, and, by Lemma $7(\mathrm{~A})$, we have $u=T u$.

In the next theorem we will show that $u$ is a unique fixed point of $T$.

Theorem 26. Adding condition $(U)$ to the hypotheses of Theorem 24 (resp., Theorem 25), one obtains that $u$ is the unique fixed point of $T$. 
Proof. We will use the reductio ad absurdum. Let $v$ be another fixed point of $T$ with $v \neq u$ and hence $\sigma(u, v)=t>0$. By hypothesis $(U)$,

$$
1 \leq \alpha(u, v)=\alpha(T u, T v)
$$

Due to inequality (42) we have

$$
\begin{gathered}
\alpha(u, v) \sigma(T u, T v) \\
\leq \phi(\psi(\sigma(u, v)), \psi(\sigma(u, T u)), \psi(\sigma(v, T v)), \\
\psi(\sigma(u, T v)), \psi(\sigma(v, T u))) \\
-\xi(\max \{\sigma(u, v), \sigma(u, T u), \sigma(v, T v), \\
\left.\left.\frac{\sigma(u, T v)+\sigma(v, T u)}{4}\right\}\right) .
\end{gathered}
$$

Taking property $\left(\phi_{2}\right)$ into account, we get that

$$
t \leq(t, 0,0, t, t)-\xi(t)<t-\xi(t)
$$

which is a contradiction. Hence, $\sigma(u, v)=0$. By Lemma $7(\mathrm{~A})$ we get that $u=v$. Thus we proved that $u$ is the unique fixed point of $T$.

\section{Fixed Point Theorems via the Weaker Meir-Keeler Function $\mu$}

In the section, we will investigate the existence and uniqueness of a fixed point of certain mappings by using the MeirKeeler function. Now, we recall the notion of the weaker Meir-Keeler function $\mu:[0, \infty) \rightarrow[0, \infty)$.

Definition 27 (see [28]). One calls $\mu:[0, \infty) \rightarrow[0, \infty)$ a weaker Meir-Keeler function if, for each $\eta>0$, there exists $\delta>0$ such that, for $t \in[0, \infty)$ with $\eta \leq t<\eta+\delta$, there exists $n_{0} \in \mathbb{N}$ such that $\mu^{n_{0}}(t)<\eta$.

One denotes by $\mathscr{M}$ the class of nondecreasing functions $\mu:[0, \infty) \rightarrow[0, \infty)$ satisfying the following conditions:

$\left(\mu_{1}\right) \mu:[0, \infty) \rightarrow[0, \infty)$ is a weaker Meir-Keeler function;

$\left(\mu_{2}\right) \mu(t)>0$ for $t>0$ and $\mu(0)=0$;

$\left(\mu_{3}\right)$ for all $t>0,\left\{\mu^{n}(t)\right\}_{n \in \mathbb{N}}$ is decreasing;

$\left(\mu_{4}\right)$ if $\lim _{n \rightarrow \infty} t_{n}=\gamma$, then $\lim _{n \rightarrow \infty} \mu\left(t_{n}\right) \leq \gamma$.

And one denotes by $\Theta$ the class of functions $\varphi:[0, \infty) \rightarrow$ $[0, \infty)$ satisfying the following conditions:

$\left(\varphi_{1}\right) \varphi$ is continuous;

$$
\left(\varphi_{2}\right) \varphi(t)>0 \text { for } t>0 \text { and } \varphi(0)=0 \text {. }
$$

We state the notion of the generalized weaker Meir-Keeler type $(\mu, \varphi)$ - $\alpha$-contractive mappings in metric-like spaces as follows.
Definition 28. Let $(X, \sigma)$ be a metric-like space, and let $\alpha$ : $X \times X \rightarrow \mathbb{R}^{+}$. One says that $T: Y \rightarrow Y$ is called a generalized weaker Meir-Keeler type $\alpha$ - $(\mu, \varphi)$-contractive mapping if $T$ is $\alpha$-admissible and satisfies

$$
\alpha(x, y) \sigma(T x, T y) \leq \mu(M(x, y))-\varphi(M(x, y))
$$

for all $x, y \in X$, where $\mu \in \mathscr{M}, \varphi \in \Theta$, and

$$
\begin{gathered}
M(x, y)=\max \{\sigma(x, y), \sigma(x, f x), \sigma(y, f y), \\
\left.\frac{\sigma(x, f y)+\sigma(y, f x)}{4}\right\} .
\end{gathered}
$$

The main result of this section is the following.

Theorem 29. Let $(X, \sigma)$ be a complete metric-like space and let $T: X \rightarrow X$ be a generalized weaker Meir-Keeler type $\alpha$ $(\mu, \varphi)$-contractive mapping where $\alpha$ is transitive. Suppose that

(i) $T$ is $\alpha$-admissible;

(ii) there exists $x_{0} \in X$ such that $\alpha\left(x_{0}, T x_{0}\right) \geq 1$;

(iii) $T$ is continuous.

Then there exists $u \in X$ such that $T u=u$.

Proof. Following the lines in the proof of Theorem 20, we construct an iterative sequence $\left\{x_{n}\right\}$ in $X$ as follows:

$$
x_{n+1}=T x_{n}=T^{n+1} x_{0} \quad \forall n \geq 0 .
$$

If we have $x_{n_{0}}=x_{n_{0}+1}$, for some $n_{0}$, then the proof is completed. Indeed, $u=x_{n_{0}}$ is a fixed point of $T$. Hence, from now on, we assume that

$$
x_{n} \neq x_{n+1} \quad \forall n \text {. }
$$

Moreover, due to Lemmas 7(C) and (D), we have

$$
\sigma\left(x_{n}, x_{n+1}\right)>0 \text {. }
$$

Again, by following the lines in the proof of Theorem 20, we get that

$$
\alpha\left(x_{n}, x_{n+1}\right) \geq 1, \quad \forall n=0,1, \ldots
$$

We divide the proof into three steps.

Step 1. We will prove that $\lim _{n \rightarrow \infty} \sigma\left(x_{n}, x_{n+1}\right)=0$. Since $T$ is a generalized weaker Meir-Keeler type $\alpha$ - $(\mu, \varphi)$-contractive mapping, by taking $x=x_{n-1}$ and $y=x_{n}$ in (67), we have

$$
\begin{aligned}
\sigma\left(x_{n}, x_{n+1}\right) & =\sigma\left(T x_{n-1}, T x_{n}\right) \\
& \leq \alpha\left(x_{n-1}, x_{n}\right) \sigma\left(T x_{n-1}, T x_{n}\right) \\
& \leq \mu\left(M\left(x_{n-1}, x_{n}\right)\right)-\varphi\left(M\left(x_{n-1}, x_{n}\right)\right),
\end{aligned}
$$


where

$$
\begin{aligned}
& M\left(x_{n-1}, x_{n}\right)=\max \left\{\sigma\left(x_{n-1}, x_{n}\right), \sigma\left(x_{n-1}, T x_{n-1}\right),\right. \\
& \sigma\left(x_{n}, T x_{n}\right), \\
& \left.\frac{\sigma\left(x_{n-1}, T x_{n}\right)+\sigma\left(x_{n}, T x_{n-1}\right)}{4}\right\} \\
& =\max \left\{\sigma\left(x_{n-1}, x_{n}\right), \sigma\left(x_{n-1}, x_{n}\right)\right. \text {, } \\
& \sigma\left(x_{n}, x_{n+1}\right), \\
& \left.\frac{\sigma\left(x_{n-1}, x_{n+1}\right)+\sigma\left(x_{n}, x_{n}\right)}{4}\right\} \\
& =\max \left\{\sigma\left(x_{n-1}, x_{n}\right), \sigma\left(x_{n}, x_{n+1}\right)\right. \text {, } \\
& \left.\frac{\sigma\left(x_{n-1}, x_{n}\right)+\sigma\left(x_{n}, x_{n+1}\right)}{2}\right\} \\
& =\max \left\{\sigma\left(x_{n-1}, x_{n}\right), \sigma\left(x_{n}, x_{n+1}\right)\right\} .
\end{aligned}
$$

If $M\left(x_{n-1}, x_{n}\right)=\sigma\left(x_{n}, x_{n+1}\right)$, then, by (73) and the properties of the functions $\mu$ and $\varphi$, we have

$$
\begin{aligned}
\sigma\left(x_{n}, x_{n+1}\right)= & \sigma\left(T x_{n-1}, T x_{n}\right) \\
& \leq \alpha\left(x_{n-1}, x_{n}\right) \sigma\left(T x_{n-1}, T x_{n}\right) \\
& \leq \mu\left(\sigma\left(x_{n}, x_{n+1}\right)\right)-\varphi\left(\sigma\left(x_{n}, x_{n+1}\right)\right) \\
& \leq \mu\left(\sigma\left(x_{n}, x_{n+1}\right)\right) .
\end{aligned}
$$

Since $\left\{\mu^{n}(t)\right\}_{n \in \mathbb{N}}$ is decreasing, the inequality above yields a contradiction. Thus, we conclude that $M\left(x_{n-1}, x_{n}\right)=$ $\sigma\left(x_{n-1}, x_{n}\right)$ and inequality (71) becomes

$$
\sigma\left(x_{n}, x_{n+1}\right) \leq \mu\left(\sigma\left(x_{n-1}, x_{n}\right)\right) \text {, }
$$

for all $n \in \mathbb{N}$. Recursively, we conclude that

$$
\sigma\left(x_{n}, x_{n+1}\right) \leq \mu^{n}\left(\sigma\left(x_{0}, x_{1}\right)\right),
$$

for all $n \in \mathbb{N}$.

Since $\left\{\mu^{n}\left(\sigma\left(x_{0}, x_{1}\right)\right)\right\}_{n \in \mathbb{N}}$ is decreasing, it must converge to some $\eta \geq 0$. We claim that $\eta=0$. On the contrary, assume that $\eta>0$. Then, by the definition of the weaker Meir-Keeler function $\mu$, there exists $\delta>0$ such that, for $x_{0}, x_{1} \in X$ with $\eta \leq \sigma\left(x_{0}, x_{1}\right)<\delta+\eta$, there exists $n_{0} \in \mathbb{N}$ such that $\mu^{n_{0}}\left(\sigma\left(x_{0}, x_{1}\right)\right)<\eta$. Since $\lim _{n \rightarrow \infty} \mu^{n}\left(\sigma\left(x_{0}, x_{1}\right)\right)=\eta$, there exists $p_{0} \in \mathbb{N}$ such that $\eta \leq \mu^{p}\left(\sigma\left(x_{0}, x_{1}\right)\right)<\delta+\eta$, for all $p \geq p_{0}$. Thus, we conclude that $\mu^{p_{0}+n_{0}}\left(\sigma\left(x_{0}, x_{1}\right)\right)<\eta$. So we get a contradiction. Therefore $\lim _{n \rightarrow \infty} \mu^{n}\left(\sigma\left(x_{0}, x_{1}\right)\right)=0$; that is,

$$
\lim _{n \rightarrow \infty} \sigma\left(x_{n}, x_{n+1}\right)=0
$$

Step 2. We prove that $\left\{x_{n}\right\}$ is a $\sigma$-Cauchy sequence.

We will use the method of reductio ad absurdum, as in the proof of Theorem 20. Suppose, on the contrary, that $\left\{x_{n}\right\}$ is not a $\sigma$-Cauchy sequence. Hence, there exists $\epsilon>0$ and subsequences $\left\{x_{n_{k}}\right\}$ and $\left\{x_{m_{k}}\right\}$ of $\left\{x_{n}\right\}$ with $m_{k}>n_{k} \geq k$ satisfying

$$
\sigma\left(x_{m_{k}}, x_{n_{k}}\right) \geq \epsilon, \quad \sigma\left(x_{m_{k}-1}, x_{n_{k}}\right)<\epsilon .
$$

By repeating the related lines in the proof of Theorem 20, we find the following limits:

$$
\begin{aligned}
\lim _{n \rightarrow \infty} \sigma\left(x_{m_{k}}, x_{n_{k}}\right) & =\lim _{n \rightarrow \infty} \sigma\left(x_{m_{k}+1}, x_{n_{k}}\right) \\
& =\lim _{n \rightarrow \infty} \sigma\left(x_{m_{k}}, x_{n_{k}+1}\right) \\
& =\lim _{n \rightarrow \infty} \sigma\left(x_{m_{k}+1}, x_{n_{k}+1}\right)=\epsilon .
\end{aligned}
$$

By the assumption of the theorem, we have

$$
\begin{aligned}
\sigma\left(x_{n_{k}+1}, x_{m_{k}+1}\right) & =\alpha\left(x_{n_{k}}, x_{m_{k}}\right) \sigma\left(T x_{n_{k}}, T x_{m_{k}}\right) \\
& \leq \mu\left(M\left(x_{n_{k}}, x_{m_{k}}\right)\right)-\varphi\left(M\left(x_{n_{k}}, x_{m_{k}}\right)\right),
\end{aligned}
$$

where

$$
\begin{gathered}
M\left(x_{n_{k}}, x_{m_{k}}\right) \\
=\max \left\{\sigma\left(x_{n_{k}}, x_{m_{k}}\right), \sigma\left(x_{n_{k}}, T x_{n_{k}}\right), \sigma\left(x_{m_{k}}, T x_{m_{k}}\right),\right. \\
\left.\frac{\sigma\left(x_{n_{k}}, T x_{m_{k}}\right)+\sigma\left(x_{m_{k}}, T x_{n_{k}}\right)}{4}\right\} \\
=\max \left\{\sigma\left(x_{n_{k}}, x_{m_{k}}\right), \sigma\left(x_{n_{k}}, x_{n_{k}+1}\right), \sigma\left(x_{m_{k}}, x_{m_{k}+1}\right),\right. \\
\left.\frac{\sigma\left(x_{n_{k}}, x_{m_{k}+1}\right)+\sigma\left(x_{m_{k}}, x_{n_{k}+1}\right)}{4}\right\} .
\end{gathered}
$$

Case 1. If $M\left(x_{n_{k}}, x_{m_{k}}\right)=\sigma\left(x_{n_{k}}, x_{m_{k}}\right)$, letting $n \rightarrow \infty$, then (81) becomes

$$
\epsilon \leq \epsilon-\varphi(\epsilon)
$$

which yields that $\varphi(\epsilon)=0$, and so we conclude that $\epsilon=0$. Therefore, we get a contradiction.

Case 2. If $M\left(x_{n_{k}}, x_{m_{k}}\right)=\sigma\left(x_{n_{k}}, x_{n_{k}+1}\right)$ or $M\left(x_{n_{k}}, x_{m_{k}}\right)=$ $\sigma\left(x_{m_{k}}, x_{m_{k}+1}\right)$, letting $n \rightarrow \infty$, then (81) turns into

$$
\epsilon \leq \mu(0)-\varphi(0)=0,
$$

which yields that $\epsilon=0$. It is a contradiction.

Case 3. If $M\left(x_{n_{k}}, x_{m_{k}}\right)=\left(\sigma\left(x_{n_{k}}, x_{m_{k}+1}\right)+\sigma\left(x_{m_{k}}, x_{n_{k}+1}\right)\right) / 4$, letting $n \rightarrow \infty$, then (81) becomes

$$
\epsilon \leq \epsilon-\varphi\left(\frac{\epsilon}{2}\right)
$$


which yields that $\varphi(\epsilon / 2)=0$, and hence $\epsilon=0$. So, we get a contradiction.

Following the arguments above, we show also that $\left\{x_{n}\right\}$ is a $\sigma$-Cauchy sequence.

Step 3. In this step, we prove that $T$ has a fixed point $u \in$ $X$. Since $(X, \sigma)$ is complete, there exists $u \in X$ such that $\lim _{n \rightarrow \infty} x_{n}=u$; equivalently,

$$
\sigma(u, u)=\lim _{n \rightarrow \infty} \sigma\left(x_{n}, u\right)=\lim _{m, n \rightarrow \infty} \sigma\left(x_{n}, x_{m}\right)=0 .
$$

Since $T$ is continuous, we obtain from (86) that

$$
\lim _{n \rightarrow \infty} \sigma\left(T x_{n}, T u\right)=\lim _{n \rightarrow \infty}=\sigma\left(x_{n}, u\right)=\sigma(u, u)=0 .
$$

Due to Lemma 8, we also have

$$
\lim _{n \rightarrow \infty} \sigma\left(x_{n}, T u\right)=\sigma(u, T u) .
$$

On account of (58)-(88) and Lemma 7(A), we derive that $u$ is a fixed point of $T$; that is, $T u=u$.

Theorem 30. Let $(X, \sigma)$ be a complete metric-like space and let $T: X \rightarrow X$ be a generalized weaker Meir-Keeler type $\alpha$ $(\mu, \varphi)$-contractive mapping where $\alpha$ is transitive. Suppose that

(i) $T$ is $\alpha$-admissible;

(ii) there exists $x_{0} \in X$ such that $\alpha\left(x_{0}, T x_{0}\right) \geq 1$;

(iii) if $\left\{x_{n}\right\}$ is a sequence in $X$ such that $\alpha\left(x_{n}, x_{n+1}\right) \geq 1$ for all $n$ and $x_{n} \rightarrow x \in X$ as $n \rightarrow \infty$, then $\alpha\left(x_{n}, x\right) \geq 1$ for all $n$.

Then there exists $u \in X$ such that $T u=u$.

Proof. Following the proof of Theorem 29, we know that the sequence $\left\{x_{n}\right\}$ defined by $x_{n+1}=T x_{n}$, for all $n \geq 0$, converges to $u$ where $u \in X$. It is enough to show that $u \in X$ is the fixed point of $T$. Suppose, on the contrary, that $\sigma(T u, u)=$ $t>0$. From (71) and condition (iii), there exists a subsequence $\left\{x_{n(k)}\right\}$ of $\left\{x_{n}\right\}$ such that $\alpha\left(x_{n(k)}, u\right) \geq 1$ for all $k$. Applying (67), for all $k$, we get that

$$
\begin{aligned}
\sigma\left(x_{n(k)+1}, T u\right)= & \sigma\left(T x_{n(k)}, T u\right) \\
\leq & \alpha\left(x_{n(k)}, u\right) \sigma\left(T x_{n(k)}, T u\right) \\
& \mu\left(M\left(x_{n(k)}, u\right)\right)-\varphi\left(M\left(x_{n(k)}, u\right)\right),
\end{aligned}
$$

where

$$
\begin{gathered}
M\left({ }_{n(k)}, u\right) \\
=\max \left\{\sigma\left(x_{n(k)}, u\right), \sigma\left(x_{n(k)}, T x_{n(k)}\right), \sigma(u, T u),\right. \\
\left.\frac{\sigma\left(x_{n(k)}, T u\right)+\sigma\left(u, T x_{n(k)}\right)}{4}\right\} \\
=\max \left\{\sigma\left(x_{n(k)}, u\right), \sigma\left(x_{n(k)}, x_{n(k)+1}\right), \sigma(u, T u),\right. \\
\left.\frac{\sigma\left(x_{n(k)}, T u\right)+\sigma\left(u, x_{n(k)+1}\right)}{4}\right\} .
\end{gathered}
$$

Theorem 32. Let $(X, \sigma)$ be a complete metric-like space and let $T: X \rightarrow X$ be a mapping. Suppose that for each $\eta>0$ there exists $\delta>0$ such that

$$
\begin{aligned}
\eta & \leq \phi(\sigma(x, y), \sigma(x, T x), \sigma(y, T y), \sigma(x, T y), \sigma(y, T x)) \\
& <\eta+\delta \longrightarrow \sigma(T x, T y)<\eta
\end{aligned}
$$

Hence, we have

$$
\sigma(u, y) \leq \mu(\sigma(u, y))-\varphi(\sigma(u, y)),
$$

since $\mu(t)-\varphi(t)<t$, for all $t>0$, which is a contradiction. Thus we proved that $u$ is the unique fixed point of $T$.

\section{Consequences}

In this section, we will demonstrate that several existing fixed point results in the literature can be deduced easily from our main results: Theorem 22, Theorem 26, and Theorem 31.

5.1. Standard Fixed Point Theorems. If we substitute $\alpha(x, y)=$ 1 for all $x, y \in X$ in Theorem 22, we derive immediately the following fixed point theorem. 
for all $x, y \in X$ and $\phi \in \Phi$. Then there exists a unique fixed point $u \in X$ such that $T u=u$.

If we take $\alpha(x, y)=1$ for all $x, y \in X$ in Theorem 26, we get the following fixed point theorem.

Theorem 33. Let $(X, \sigma)$ be a metric-like space and let $T$ : $X \rightarrow X$ be self-mapping. Suppose that $T$ satisfies the following inequality:

$$
\begin{gathered}
\varphi(\sigma(T x, T y)) \\
\leq \phi(\psi(\sigma(x, y)), \psi(\sigma(x, T x)), \psi(\sigma(y, T y)), \\
\psi(\sigma(x, T y)), \psi(\sigma(y, T x))) \\
-\xi(\max \{\sigma(x, y), \sigma(x, T x), \sigma(y, T y), \\
\left.\left.\frac{\sigma(x, T y)+\sigma(y, T x)}{4}\right\}\right),
\end{gathered}
$$

for all $x, y \in X$, where $\psi \in \Psi, \phi \in \Phi_{\psi}, \varphi \in \Theta$, and $\xi \in \Xi$. Then there exists a unique fixed point $u \in X$ such that $T u=u$.

If we take $\alpha(x, y)=1$ for all $x, y \in X$ in Theorem 31, we get the following fixed point theorem.

Theorem 34. Let $(X, \sigma)$ be a complete metric-like space and let $T: X \rightarrow X$ be mapping. Suppose that $T$ satisfies

$$
\sigma(T x, T y) \leq \mu(M(x, y))-\varphi(M(x, y)),
$$

for all $x, y \in X$, where $\mu \in \mathscr{M}, \varphi \in \Theta$, and

$$
\begin{gathered}
M(x, y)=\max \{\sigma(x, y), \sigma(x, f x), \sigma(y, f y), \\
\left.\frac{\sigma(x, f y)+\sigma(y, f x)}{4}\right\} .
\end{gathered}
$$

Then there exists a unique fixed point $u \in X$ such that $T u=u$.

5.2. Fixed Point Theorems on Metric Spaces Endowed with a Partial Order. In the last decade, the investigation of the existence of fixed point on metric spaces endowed with partial orders has been appreciated by several authors. The initial results in this direction were reported by Turinici [29], Ran and Reurings in [30]. Now, we consider the partially ordered versions of our theorems. For this purpose, we need to recall some concepts.

Definition 35 . Let $(X, \preccurlyeq)$ be a partially ordered set and let $T: X \rightarrow X$ be a given mapping. One says that $T$ is nondecreasing with respect to $\preccurlyeq$ if

$$
x, y \in X, \quad x \leqslant y \Longrightarrow T x \leqslant T y .
$$

Definition 36 . Let $(X, \preccurlyeq)$ be a partially ordered set. A sequence $\left\{x_{n}\right\} \subset X$ is said to be nondecreasing with respect to $\preccurlyeq$ if $x_{n} \preccurlyeq x_{n+1}$ for all $n$.
Definition 37 . Let $(X, \preccurlyeq)$ be a partially ordered set and let $d$ be a metric on $X$. One says that $(X, \preccurlyeq, d)$ is regular if, for every nondecreasing sequence $\left\{x_{n}\right\} \subset X$ such that $x_{n} \rightarrow x \in X$ as $n \rightarrow \infty$, there exists a subsequence $\left\{x_{n(k)}\right\}$ of $\left\{x_{n}\right\}$ such that $x_{n(k)} \leqslant x$ for all $k$.

Theorem 38. Let $(X, \sigma)$ be a complete metric-like space and let $T: X \rightarrow X$ be a mapping. Suppose that for each $\eta>0$ there exists $\delta>0$ such that

$$
\begin{aligned}
\eta & \leq \phi(\sigma(x, y), \sigma(x, T x), \sigma(y, T y), \sigma(x, T y), \sigma(y, T x)) \\
& <\eta+\delta \longrightarrow \sigma(T x, T y)<\eta
\end{aligned}
$$

for all $x, y \in X$ and $\phi \in \Phi$. Then there exists a unique fixed point $u \in X$ such that $T u=u$.

We have the following result.

Corollary 39. Let $(X, \preccurlyeq)$ be a partially ordered set and let $\sigma$ be a metric-like mapping on $X$ such that $(X, \sigma)$ is complete metriclike space. Let $T: X \rightarrow X$ be a nondecreasing mapping with respect to $\preccurlyeq$. Suppose that for each $\eta>0$ there exists $\delta>0$ such that

$$
\begin{aligned}
\eta & \leq \phi(\sigma(x, y), \sigma(x, T x), \sigma(y, T y), \sigma(x, T y), \sigma(y, T x)) \\
& <\eta+\delta \longrightarrow \sigma(T x, T y)<\eta
\end{aligned}
$$

for all $x, y \in X$ with $x \geqslant y$ and $\phi \in \Phi$. Suppose also that the following conditions hold:

(i) there exists $x_{0} \in X$ such that $x_{0} \leqslant T x_{0}$;

(ii) $T$ is continuous or $(X, \preccurlyeq, \sigma)$ is regular.

Then $T$ has a fixed point. Moreover, if for all $x, y \in X$ there exists $z \in X$ such that $x \leqslant z$ and $y \leqslant z$, one has uniqueness of the fixed point.

Proof. Define the mapping $\alpha: X \times X \rightarrow[0, \infty)$ by

$$
\alpha(x, y)= \begin{cases}1 & \text { if } x \leqslant y \text { or } x \geqslant y \\ 0 & \text { otherwise. }\end{cases}
$$

Clearly, for each $\eta>0$, there exists $\delta>0$ such that

$$
\begin{aligned}
\eta & \leq \phi(\sigma(x, y), \sigma(x, T x), \sigma(y, T y), \sigma(x, T y), \sigma(y, T x)) \\
& <\eta+\delta \longrightarrow \alpha(x, y) \sigma(T x, T y)<\eta
\end{aligned}
$$

for all $x, y \in X$ and $\phi \in \Phi$. From condition (i), we have $\alpha\left(x_{0}, T x_{0}\right) \geq 1$. Moreover, for all $x, y \in X$, from the monotone property of $T$, we have

$$
\begin{array}{r}
\alpha(x, y) \geq 1 \Longrightarrow x \geqslant y \text { or } x \leqslant y \Longrightarrow T x \geqslant T y \\
\text { or } \quad T x \leqslant T y \Longrightarrow \alpha(T x, T y) \geq 1 .
\end{array}
$$

Thus $T$ is $\alpha$-admissible. Now, if $T$ is continuous, the existence of a fixed point follows from Theorem 20. Suppose now that 
$(X, \preccurlyeq, \sigma)$ is regular. Let $\left\{x_{n}\right\}$ be a sequence in $X$ such that $\alpha\left(x_{n}, x_{n+1}\right) \geq 1$ for all $n$ and $x_{n} \rightarrow x \in X$ as $n \rightarrow \infty$. From the regularity hypothesis, there exists a subsequence $\left\{x_{n(k)}\right\}$ of $\left\{x_{n}\right\}$ such that $x_{n(k)} \leqslant x$ for all $k$. This implies from the definition of $\alpha$ that $\alpha\left(x_{n(k)}, x\right) \geq 1$ for all $k$. In this case, the existence of a fixed point follows from Theorem 21. To show the uniqueness, let $x, y \in X$. By the hypothesis, there exists $z \in X$ such that $x \leqslant z$ and $y \leqslant z$, which implies from the definition of $\alpha$ that $\alpha(x, z) \geq 1$ and $\alpha(y, z) \geq 1$. Thus we deduce the uniqueness of the fixed point by Theorem 22 .

By using the same argument in the proof of Corollary 39, we can conclude the following two corollaries. We omit the proofs of these corollaries to avoid the repetition.

Corollary 40. Let $(X, \preccurlyeq)$ be a partially ordered set and let $\sigma$ be a metric-like mapping on $X$ such that $(X, \sigma)$ is complete metriclike space. Let $T: X \rightarrow X$ be a nondecreasing mapping with respect to $\preccurlyeq$. Suppose that $T$ satisfies the following inequality:

$$
\begin{aligned}
& \varphi(\sigma(T x, T y)) \\
& \leq \phi(\psi(\sigma(x, y)), \psi(\sigma(x, T x)), \psi(\sigma(y, T y)), \\
&\psi(\sigma(x, T y)), \psi(\sigma(y, T x))) \\
&-\xi(\max \{\sigma(x, y), \sigma(x, T x), \sigma(y, T y), \\
&\left.\left.\frac{\sigma(x, T y)+\sigma(y, T x)}{4}\right\}\right),
\end{aligned}
$$

for all $x, y \in X$ with $x \geqslant y$, where $\psi \in \Psi, \phi \in \Phi_{\psi}, \varphi \in \Theta$, and $\xi \in \Xi$.

Suppose also that the following conditions hold:

(i) there exists $x_{0} \in X$ such that $x_{0} \leqslant T x_{0}$;

(ii) $T$ is continuous or $(X, \preccurlyeq, \sigma)$ is regular.

Then $T$ has a fixed point. Moreover, if for all $x, y \in X$ there exists $z \in X$ such that $x \leqslant z$ and $y \leqslant z$, one has uniqueness of the fixed point.

Corollary 41. Let $(X, \preccurlyeq)$ be a partially ordered set and $\sigma$ be a metric-like mapping on $X$ such that $(X, \sigma)$ is complete metriclike space. Let $T: X \rightarrow X$ be a nondecreasing mapping with respect to $\preccurlyeq$. Suppose that $T$ satisfies

$$
\sigma(T x, T y) \leq \mu(M(x, y))-\varphi(M(x, y)),
$$

for all $x, y \in X$ with $x \geqslant y$, where $\mu \in \mathscr{M}, \varphi \in \Theta$, and

$$
\begin{gathered}
M(x, y)=\max \{\sigma(x, y), \sigma(x, f x), \sigma(y, f y), \\
\left.\frac{\sigma(x, f y)+\sigma(y, f x)}{4}\right\} .
\end{gathered}
$$

Suppose also that the following conditions hold:

(i) there exists $x_{0} \in X$ such that $x_{0} \leqslant T x_{0}$;

(ii) $T$ is continuous or $(X, \preccurlyeq, \sigma)$ is regular.
Then $T$ has a fixed point. Moreover, if for all $x, y \in X$ there exists $z \in X$ such that $x \leqslant z$ and $y \leqslant z$, one has uniqueness of the fixed point.

5.3. Fixed Point Theorems for Cyclic Contractive Mappings. In this subsection, we consider the cyclic contraction and related fixed point as a consequence of our main results. Notice that this trend was initiated by Kirk et al. [31]. Following this paper [31], a number of fixed point theorems for cyclic contractive mappings have been reported (see, e.g., [32-37]).

We have the following result.

Corollary 42. Let $\left\{A_{i}\right\}_{i=1}^{2}$ be nonempty closed subsets of a complete metric-like space $(X, \sigma)$ and let $T: Y \rightarrow Y$ be a given mapping such that

$$
\text { (I) } T\left(A_{1}\right) \subseteq A_{2} \text { and } T\left(A_{2}\right) \subseteq A_{1} \text {, }
$$

where $Y=A_{1} \cup A_{2}$. Suppose that for each $\eta>0$ there exists $\delta>0$ such that

$$
\begin{aligned}
\eta & \leq \phi(\sigma(x, y), \sigma(x, T x), \sigma(y, T y), \sigma(x, T y), \sigma(y, T x)) \\
& <\eta+\delta \longrightarrow \sigma(T x, T y)<\eta
\end{aligned}
$$

for all $(x, y) \in A_{1} \times A_{2}$ and $\phi \in \Phi$. Then $T$ has a unique fixed point that belongs to $A_{1} \cap A_{2}$.

Proof. Since $A_{1}$ and $A_{2}$ are closed subsets of the complete metric space $(X, d)$, then $(Y, d)$ is complete. Define the mapping $\alpha: Y \times Y \rightarrow[0, \infty)$ by

$$
\alpha(x, y)= \begin{cases}1 & \text { if }(x, y) \in\left(A_{1} \times A_{2}\right) \cup\left(A_{2} \times A_{1}\right) \\ 0 & \text { otherwise }\end{cases}
$$

From (111) and the definition of $\alpha$, for each $\eta>0$, there exists $\delta>0$ such that

$$
\begin{aligned}
\eta & \leq \phi(\sigma(x, y), \sigma(x, T x), \sigma(y, T y), \sigma(x, T y), \sigma(y, T x)) \\
& <\eta+\delta \longrightarrow \alpha(x, y) \sigma(T x, T y)<\eta
\end{aligned}
$$

for all $(x, y) \in A_{1} \times A_{2}$ and $\phi \in \Phi$. Thus $T$ satisfies the contractive condition (104).

Let $(x, y) \in Y \times Y$ such that $\alpha(x, y) \geq 1$. If $(x, y) \in A_{1} \times A_{2}$, from (I), $(T x, T y) \in A_{2} \times A_{1}$, which implies that $\alpha(T x, T y) \geq$ 1. If $(x, y) \in A_{2} \times A_{1}$, from (I), $(T x, T y) \in A_{1} \times A_{2}$, which implies that $\alpha(T x, T y) \geq 1$. Thus, in all cases, we have $\alpha(T x, T y) \geq 1$. This implies that $T$ is $\alpha$-admissible.

Also, from (I), for any $a \in A_{1}$, we have $(a, T a) \in A_{1} \times A_{2}$, which implies that $\alpha(a, T a) \geq 1$.

Now, let $\left\{x_{n}\right\}$ be a sequence in $X$ such that $\alpha\left(x_{n}, x_{n+1}\right) \geq 1$ for all $n$ and $x_{n} \rightarrow x \in X$ as $n \rightarrow \infty$. This implies from the definition of $\alpha$ that

$$
\left(x_{n}, x_{n+1}\right) \in\left(A_{1} \times A_{2}\right) \cup\left(A_{2} \times A_{1}\right), \quad \forall n .
$$

Since $\left(A_{1} \times A_{2}\right) \cup\left(A_{2} \times A_{1}\right)$ is a closed set with respect to the Euclidean metric, we get that

$$
(x, x) \in\left(A_{1} \times A_{2}\right) \cup\left(A_{2} \times A_{1}\right),
$$


which implies that $x \in A_{1} \cap A_{2}$. Thus we get immediately from the definition of $\alpha$ that $\alpha\left(x_{n}, x\right) \geq 1$ for all $n$.

Let $x, y \in X$ be distinct fixed points of $T$ from (I); this implies that $x, y \in A_{1} \cap A_{2}$. So, for any $z \in Y$, we have $\alpha(x, z) \geq 1$ and $\alpha(y, z) \geq 1$. Thus condition $(U)$ is satisfied.

Now, all the hypotheses of Theorem 22 are satisfied; we deduce that $T$ has a unique fixed point that belongs to $A_{1} \cap A_{2}$ (from (I)).

As in the previous section, we can conclude the following two corollaries by using the same argument in the proof of Corollary 42. We omit the proofs of the following corollaries to avoid the repetition.

Corollary 43. Let $\left\{A_{i}\right\}_{i=1}^{2}$ be nonempty closed subsets of a complete metric-like space $(X, \sigma)$ and let $T: Y \rightarrow Y$ be a given mapping such that

(I) $T\left(A_{1}\right) \subseteq A_{2}$ and $T\left(A_{2}\right) \subseteq A_{1}$, where $Y=A_{1} \cup A_{2}$. Suppose that $T$ satisfies the following inequality:

$$
\begin{aligned}
& \varphi(\sigma(T x, T y)) \\
& \leq \phi \psi(\sigma(x, y)), \psi(\sigma(x, T x)), \psi(\sigma(y, T y)), \\
&\psi(\sigma(x, T y)), \psi(\sigma(y, T x))) \\
&-\xi(\max \{\sigma(x, y), \sigma(x, T x), \sigma(y, T y), \\
&\left.\left.\frac{\sigma(x, T y)+\sigma(y, T x)}{4}\right\}\right),
\end{aligned}
$$

for all $(x, y) \in A_{1} \times A_{2}$, where $\psi \in \Psi, \phi \in \Phi_{\psi}, \varphi \in \Theta$, and $\xi \in \Xi$. Then $T$ has a unique fixed point that belongs to $A_{1} \cap A_{2}$.

Corollary 44. Let $\left\{A_{i}\right\}_{i=1}^{2}$ be nonempty closed subsets of a complete metric-like space $(X, \sigma)$ and let $T: Y \rightarrow Y$ be a given mapping such that

(I) $T\left(A_{1}\right) \subseteq A_{2}$ and $T\left(A_{2}\right) \subseteq A_{1}$, where $Y=A_{1} \cup A_{2}$. Suppose that $T$ satisfies

$$
\sigma(T x, T y) \leq \mu(M(x, y))-\varphi(M(x, y)),
$$

for all $(x, y) \in A_{1} \times A_{2}$, where $\mu \in \mathscr{M}, \varphi \in \Theta$, and

$$
\begin{gathered}
M(x, y)=\max \{\sigma(x, y), \sigma(x, f x), \sigma(y, f y), \\
\left.\frac{\sigma(x, f y)+\sigma(y, f x)}{4}\right\} .
\end{gathered}
$$

Then $T$ has a unique fixed point that belongs to $A_{1} \cap A_{2}$.

\section{Conflict of Interests}

The authors declare that they have no conflict of interests.

\section{Authors' Contribution}

All authors contributed equally and significantly to writing this paper. All authors read and approved the final paper.

\section{Acknowledgments}

This research was supported by Deanship of Scientific Research (DSR), King Abdulaziz University, Jeddah, Saudi Arabia. The authors give thanks to anonymous referees for their remarkable comments, suggestion, and ideas that help to improve this paper.

\section{References}

[1] B. Samet, C. Vetro, and P. Vetro, "Fixed point theorems for $\left(\alpha^{*}, \psi\right)$-contractive type mappings," Nonlinear Analysis: Theory, Methods \& Applications, vol. 75, no. 4, pp. 2154-2165, 2012.

[2] I. A. Rus, Generalized Contractions and Applications, Cluj University Press, Cluj-Napoca, Romania, 2001.

[3] R. M. Bianchini and M. Grandolfi, "Trasformazioni di tipo contrattivo generalizzato in uno spazio metrico," Atti della Accademia Nazionale dei Lincei: Rendiconti: Classe di Scienze Fisiche, Matematiche e Naturali, vol. 45, pp. 212-216, 1968.

[4] P. D. Proinov, "A generalization of the Banach contraction principle with high order of convergence of successive approximations," Nonlinear Analysis: Theory, Methods \& Applications, vol. 67, no. 8, pp. 2361-2369, 2007.

[5] P. D. Proinov, "New general convergence theory for iterative processes and its applications to Newton-Kantorovich type theorems," Journal of Complexity, vol. 26, no. 1, pp. 3-42, 2010.

[6] B. Samet, "A fixed point theorem in a generalized metric space for mappings satisfying a contractive condition of integral type," International Journal of Mathematical Analysis, vol. 3, no. 25-28, pp. 1265-1271, 2009.

[7] M. U. Ali and T. Kamran, "On $\left(\alpha^{x} 2 a ;, \psi\right)$-contractive multivalued mappings," Fixed Point Theory and Applications, vol. 2013, article 137, 2013.

[8] M. Jleli, E. Karapınar, and B. Samet, "Best proximity points for generalized $\alpha$ - $\psi$-proximal contractive type mappings," Journal of Applied Mathematics, vol. 2013, Article ID 534127, 10 pages, 2013.

[9] M. Jleli, E. Karapınar, and B. Samet, "Fixed point results for $\alpha-\psi_{\lambda}$-contractions on gauge spaces and applications," Abstract and Applied Analysis, vol. 2013, Article ID 730825, 7 pages, 2013.

[10] E. Karapınar, "Discussion on $\alpha-\psi$ contractions on generalized metric spaces," Abstract and Applied Analysis, vol. 2014, Article ID 962784, 7 pages, 2014.

[11] E. Karapınar and B. Samet, "Generalized $\alpha-\psi$ contractive type mappings and related fixed point theorems with applications," Abstract and Applied Analysis, vol. 2012, Article ID 793486, 17 pages, 2012.

[12] M. Mohammadi, S. Rezapour, and N. Shahzad, "Some results on fixed points of-ciric generalized multifunctions," Fixed Point Theory and Applications, vol. 2013, article 24, 2013.

[13] M. Berzig and M. Rus, "Fixed point theorems for $\alpha$ contractive mappings of Meir-Keeler type and applications," http://arxiv.org/abs/1303.5798.

[14] M. Berzig and E. Karapınar, "Fixed point results for $(\alpha \psi, \beta \phi)$ contractive mappings for a generalized altering distance," Fixed Point Theory and Applications, vol. 2013, article 205, 2013. 
[15] S. G. Matthews, "Partial metric topology," in Proceedings of the 8th Summer of Conference on General Topology and Applications, vol. 728 of Annals of the New York Academy of Sciences, pp. 183-197, 1994.

[16] T. Abdeljawad, "Fixed points for generalized weakly contractive mappings in partial metric spaces," Mathematical and Computer Modelling, vol. 54, no. 11-12, pp. 2923-2927, 2011.

[17] R. P. Agarwal, M. A. Alghamdi, and N. Shahzad, "Fixed point theory for cyclic generalized contractions in partial metric spaces," Fixed Point Theory and Applications, vol. 2012, article 40, 2012.

[18] I. Altun and A. Erduran, "Fixed point theorems for monotone mappings on partial metric spaces," Fixed Point Theory and Applications, vol. 2011, Article ID 508730, 10 pages, 2011.

[19] H. Aydi, "Fixed point results for weakly contractive mappings in ordered partial metric spaces," Journal of Advanced Mathematical Studies, vol. 4, no. 2, pp. 1-12, 2011.

[20] K. P. Chi, E. Karapınar, and T. D. Thanh, "A generalized contraction principle in partial metric spaces," Mathematical and Computer Modelling, vol. 55, no. 5-6, pp. 1673-1681, 2012.

[21] E. Karapinar, "Generalizations of Caristi Kirk's theorem on partial metric spaces," Fixed Point Theory and Applications, vol. 2011, article 4, 2011.

[22] E. Karapınar, İ. M. Erhan, and A. Y. Ulus, "Fixed point theorem for cyclic maps on partial metric spaces," Applied Mathematics \& Information Sciences, vol. 6, no. 2, pp. 239-244, 2012.

[23] S. Oltra and O. Valero, "Banach's fixed point theorem for partial metric spaces," Rendiconti dell'Istituto di Matematica dell'Università di Trieste, vol. 36, no. 1-2, pp. 17-26, 2004.

[24] A. Amini-Harandi, "Metric-like spaces, partial metric spaces and fixed points," Fixed Point Theory and Applications, vol. 2012, article 204, 2012.

[25] E. Karapinar and P. Salimi, "Dislocated metric space to metric spaces with some fixed point theorems," Fixed Point Theory and Applications, vol. 2013, article 222, 2013.

[26] W. A. Kirk, P. S. Srinivasan, and P. Veeramani, "Fixed points for mappings satisfying cyclical contractive conditions," Fixed Point Theory, vol. 4, no. 1, pp. 79-89, 2003.

[27] A. Meir and E. Keeler, "A theorem on contraction mappings," Journal of Mathematical Analysis and Applications, vol. 28, pp. 326-329, 1969.

[28] C.-M. Chen, "Fixed point theory for the cyclic weaker MeirKeeler function in complete metric spaces," Fixed Point Theory and Applications, vol. 2012, article 17, 2012.

[29] M. Turinici, "Abstract comparison principles and multivariable Gronwall-Bellman inequalities," Journal of Mathematical Analysis and Applications, vol. 117, no. 1, pp. 100-127, 1986.

[30] A. C. M. Ran and M. C. B. Reurings, "A fixed point theorem in partially ordered sets and some applications to matrix equations," Proceedings of the American Mathematical Society, vol. 132, no. 5, pp. 1435-1443, 2004.

[31] W. A. Kirk, P. S. Srinivasan, and P. Veeramani, "Fixed points for mappings satisfying cyclical contractive conditions," Fixed Point Theory, vol. 4, no. 1, pp. 79-89, 2003.

[32] R. P. Agarwal, M. A. Alghamdi, and N. Shahzad, "Fixed point theory for cyclic generalized contractions in partial metric spaces," Fixed Point Theory and Applications, vol. 2012, article 40, 2012.

[33] E. Karapınar, "Fixed point theory for cyclic weak $\phi$-contraction," Applied Mathematics Letters, vol. 24, no. 6, pp. 822-825, 2011.
[34] E. Karapınar and K. Sadaranagni, "Fixed point theory for cyclic $(\phi, \psi)$-contractions," Fixed Point Theory and Applications, vol. 2011, article 69, 2011.

[35] M. Păcurar and I. A. Rus, "Fixed point theory for cyclic $\varphi$ contractions," Nonlinear Analysis: Theory, Methods \& Applications, vol. 72, no. 3-4, pp. 1181-1187, 2010.

[36] M. A. Petric, "Some results concerning cyclical contractive mappings," General Mathematics, vol. 18, no. 4, pp. 213-226, 2010.

[37] I. A. Rus, "Cyclic representations and fixed points," Annals of the Tiberiu Popoviciu Seminar of Functional Equations, Approximation and Convexity, vol. 3, pp. 171-178, 2005. 


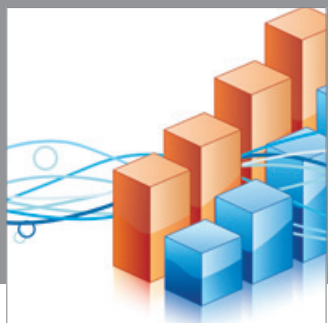

Advances in

Operations Research

mansans

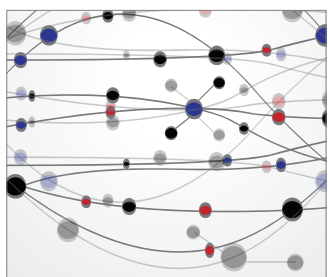

The Scientific World Journal
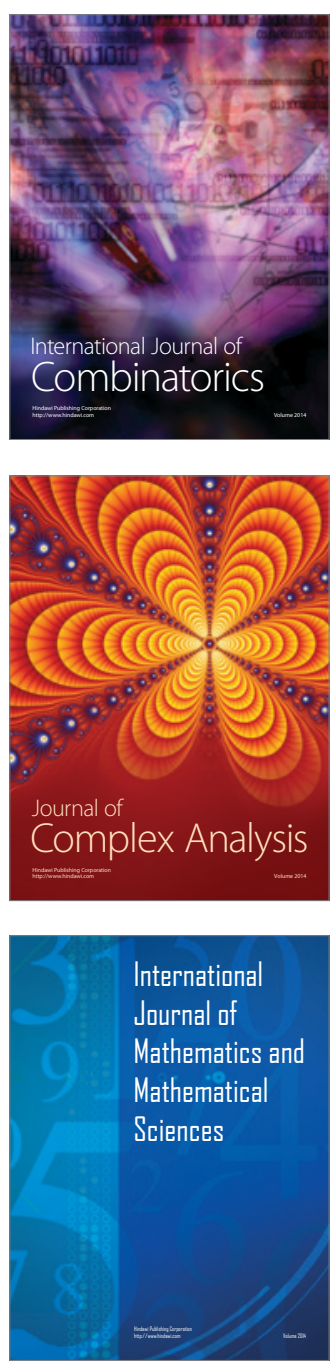
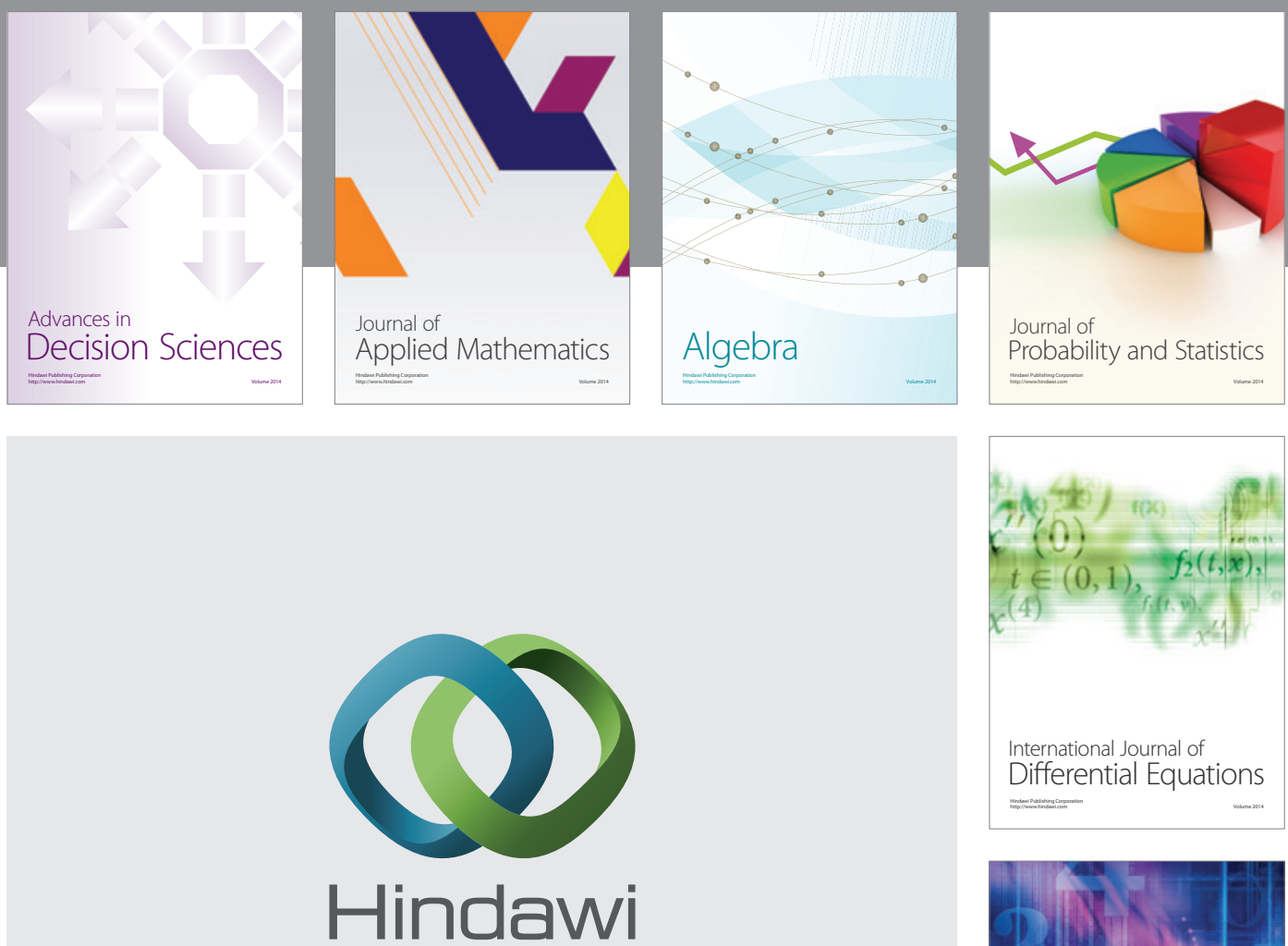

Submit your manuscripts at http://www.hindawi.com
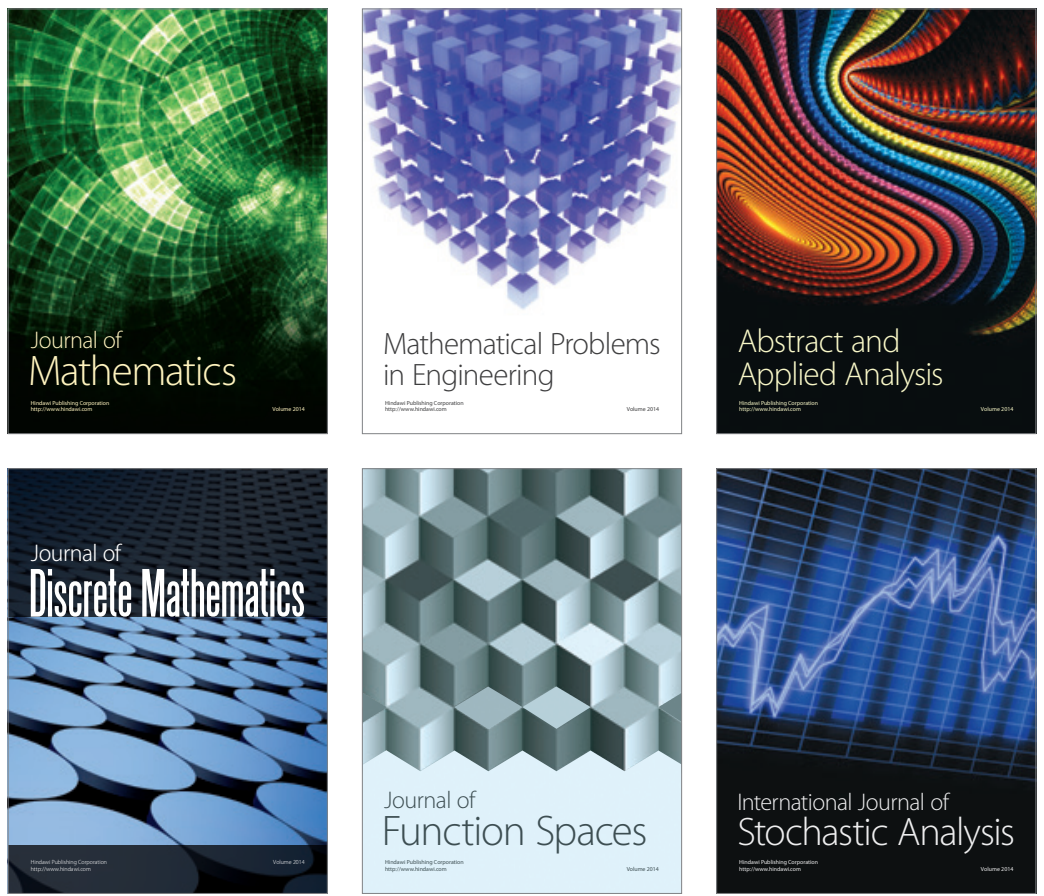

Journal of

Function Spaces

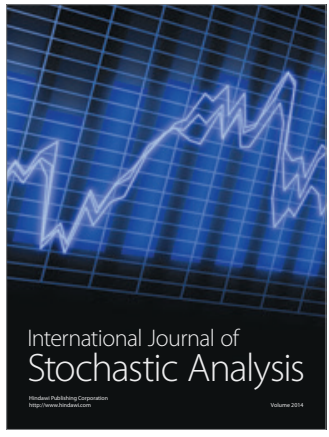

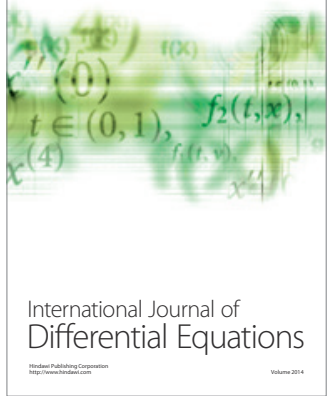
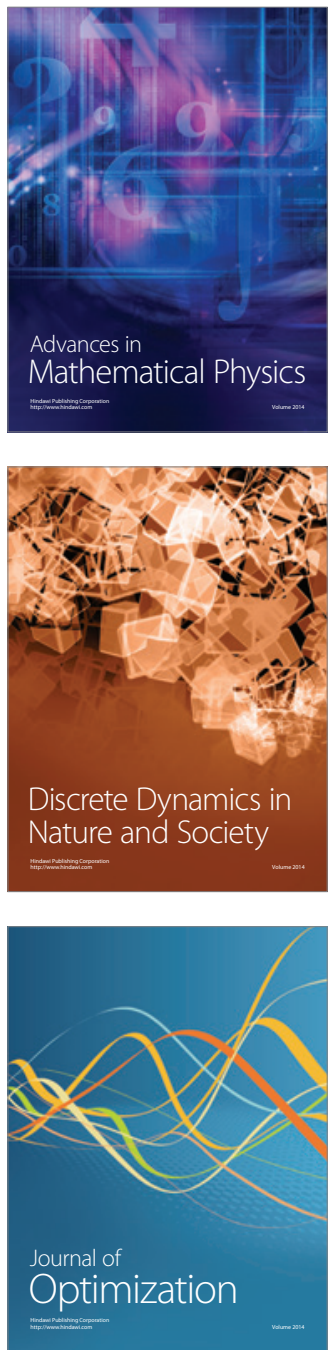